\title{
Dynamics of distinct intraseasonal oscillation in summer monsoon rainfall over the Meghalaya-Bangladesh-western Myanmar region: covariability between the tropics and mid-latitudes
}

\author{
Hatsuki Fujinami · Tetsuzo Yasunari • \\ Akihito Morimoto
}

Received: 14 September 2013/Accepted: 24 December 2013/Published online: 25 January 2014

(C) The Author(s) 2014. This article is published with open access at Springerlink.com

\begin{abstract}
Detailed spatiotemporal structures for the submonthly-scale (7-25 days) intraseasonal oscillation (ISO) in summer monsoon rainfall and atmospheric circulation were investigated in South Asia using high-quality rainfall and reanalysis datasets. The Meghalaya-Bangladesh-coast of the western Myanmar (MBWM) region is the predominant area of submonthly-scale ISO in the Asian monsoon regions. The distinct rainfall ISO is caused by a remarkable alternation of low-level zonal wind between westerly and easterly flows around the Gangetic Plain on the same timescales. In the active ISO phase of the MBWM, a strong low-level westerly/southwesterly flows around the plain and a center of cyclonic vorticity appears over Bangladesh. Hence, a local southerly flows toward the Meghalaya Plateau and there is strong southwesterly flow towards the coast along southeastern Bangladesh and western Myanmar, resulting in an increase in orographic rainfall. Rainfall also increases over the lowland area of the MBWM due to the low-level convergence in the boundary layer under the strong cyclonic circulation. The submonthly-scale lowlevel wind fluctuation around the MBWM is caused by a westward moving $n=1$ equatorial Rossby (ER) wave. When the anticyclonic (cyclonic) anomaly related to the
\end{abstract}

H. Fujinami $(\bowtie) \cdot T$. Yasunari

Hydrospheric Atmospheric Research Center, Nagoya University,

Furo-cho, Chikusa-ku, Nagoya 464-8601, Japan

e-mail: hatsuki@hyarc.nagoya-u.ac.jp

Present Address:

T. Yasunari

Research Institute for Humanity and Nature, Kyoto, Japan

A. Morimoto

Mitsubishi Electric Information Network Corporation,

Tokyo, Japan
ER wave approaches the Bay of Bengal from the western Pacific, humid westerly/southwesterly (easterly/southeasterly) flows enhance around the Gangetic Plain on the northern fringe of the anticyclone (cyclone) and in turn promote (reduce) rainfall in the MBWM. Simultaneously, robust circulation signals are observed over the mid-latitudes. In the active phase, cyclonic anomalies appear over and around the TP, having barotropic vertical structure and also contributing to the enhancement of low-level westerly flow around the Gangetic Plain. In the upper troposphere, an anticyclonic anomaly is also observed upstream of the cyclonic anomaly over the TP, having wavetrain structure. The mid-latitude circulation around the TP likely helps to induce the distinct ISO there in conjunction with the equatorial waves. Thus, the distinct ISO in the MBWM is strongly enhanced locally $(\sim 500 \mathrm{~km})$ by the terrain features, although the atmospheric circulation causing the ISO has a horizontal scale of $\sim 6,000 \mathrm{~km}$ or more, extending across the whole Asian monsoon system from the tropics to mid-latitudes.

Keywords Intraseasonal oscillation - Orographic effects · Rainfall · South Asian monsoon - Tropical-midlatitude interaction

\section{Introduction}

During the summer monsoon season (June-August), the prevailing westerly/southwesterly winds bring abundant moisture from the ocean to South Asia. A large amount of precipitation is generated by the humid monsoon flow. Land in South Asia possesses complex topographical features (Fig. 1). The interactions between the prevailing flow and the geographical features of South Asia give rise to a 
(a) Topography \& water vapor flux vectors (JJA)

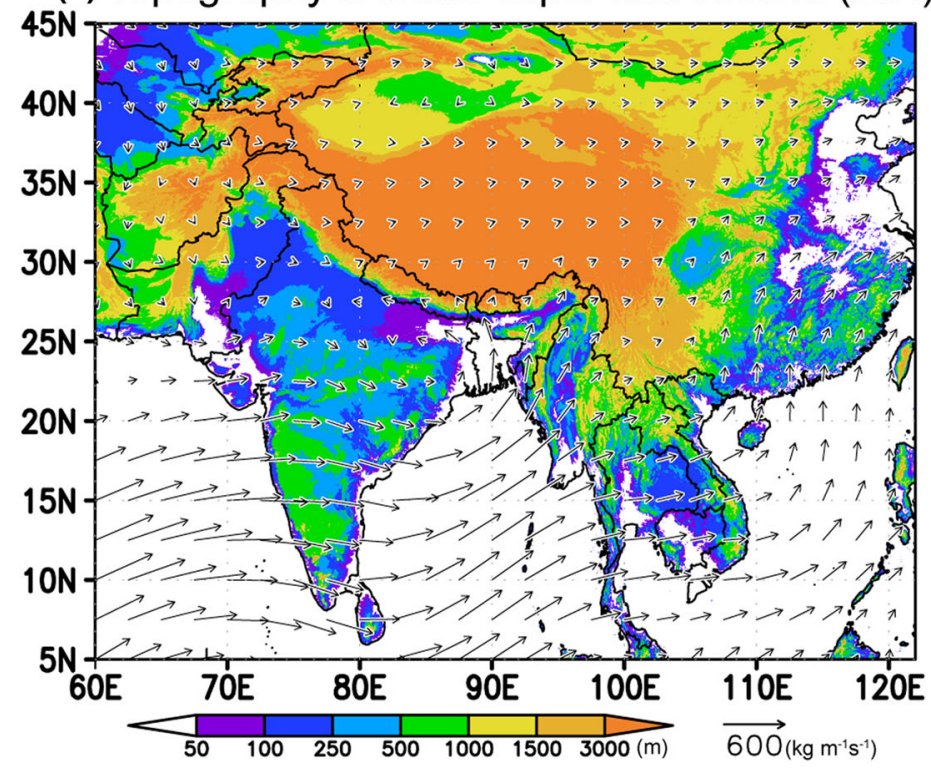

(b) Magnified view (17N-29N,83E-97E)

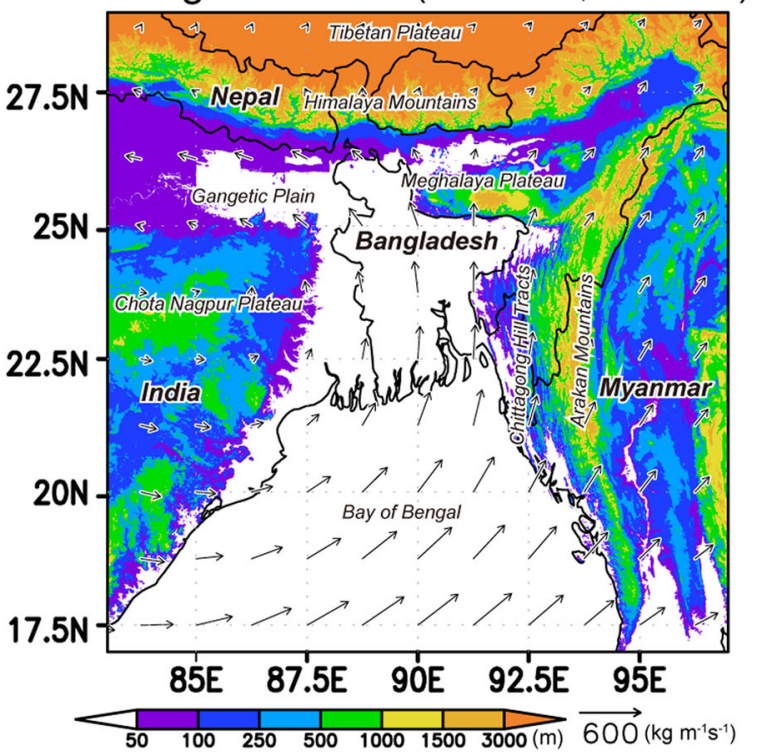

Fig. 1 a Geographic features around South Asia and climatological mean (1979-2007) vertically integrated (from the surface to $100 \mathrm{hPa}$ ) water vapor flux vectors for June-August. b As in a, but for the magnified view of the region of interest

high rainfall area near the coastal and inland mountains. Recent satellite observations, such as those by the Tropical Rainfall Measuring Mission (TRMM)-Precipitation Radar $(\mathrm{PR})$, reveal that the mean distribution of the summer monsoon rainfall is strongly influenced by the terrain distribution (e.g., Hirose et al. 2008; Romatschke and Houze 2011; Biasutti et al. 2012). Narrow mountain ranges (e.g., Arakan Mountains and Meghalaya Plateau) are important in anchoring high rainfall on the windward side. The monsoon rainfall plays an important role in forming and maintaining strong monsoon circulation through the release of latent heating due to condensation (e.g., Hoskins and Rodwell 1995; Ose 1998; Xie et al. 2006).

Monsoon precipitation does not remain constant within the summer monsoon season but exhibits clear intraseasonal oscillation (ISO) with high and low precipitation phases, referred to as active and break phases, respectively. Submonthly-scale (7-25 days)/quasi-biweekly oscillation (which are essentially the same phenomena with a spectral peak of around 14 days) and 30-60-day oscillation are the two main modes of ISOs in the Asian summer monsoon (Krishnamurti and Bhalme 1976; Murakami 1976; Yasunari 1979; Krishnamurti and Ardanuy 1980; Chen and Chen 1993; Madden and Julian 1994; Annamalai and Slingo 2001; Wang et al. 2006; Hoyos and Webster 2007; Yokoi et al. 2007; Fujinami et al. 2011; Moon et al. 2013).

The area around Bangladesh, where a tremendous amount of rainfall occurs in summer, predominantly exhibits submonthly-scale ISO, but not 30-60-day ISO (Ohsawa et al. 2000; Murata et al. 2008; Fujinami et al.
2011). The ISO feature allows the submonthly-scale ISO to modulate the total seasonal rainfall and the spatial patterns of circulation and convection around Bangladesh (Fujinami et al. 2011; hereafter referred to as FHY11).

The ISO provides different atmospheric environments in active and break phases and causes a large difference in the distribution of rainfall in each phase. However, few studies have focused on the detailed precipitation distribution related to the ISO around Bangladesh. Information about variability in the detailed rainfall distribution and precipitation characteristics during active and break phases could improve understanding of precipitation mechanisms around Bangladesh, from daily to seasonal timescales. In addition, the large variation in precipitation area is accompanied by changes in the location of the atmospheric heat source, such as diabatic heating due to latent heating from condensation. Therefore, understanding the detailed rainfall distribution and the processes underlying its variation is important for understanding the processes of formation and maintenance of the ambient atmospheric circulation.

Some previous studies have pointed out that the submonthly-scale/quasi-biweekly ISO in South/Southeast Asia is associated with a westward propagating $n=1$ equatorial Rossby (ER) wave (Chen and Chen 1993; Annamalai and Slingo 2001; Yokoi and Satomura 2005; Chatterjee and Goswami 2004; Kikuchi and Wang 2009). The ER wave has periodicity of approximately the submonthly range (Kiladis and Wheeler 1995; Masunaga 2007; Kiladis et al. 2009). However, in the submonthly-scale ISO around northeastern India and Bangladesh, the connection with 
equatorial waves is not well known. Additionally, submonthly-scale ISO is also observed over and around the Tibetan Plateau (TP) during summer (Fujinami and Yasunari 2001, 2004, 2009; Yang et al. 2010). However, the link between the mid-latitude circulation (e.g., Asian subtropical jet and Tibetan high) and the ISO around Bangladesh is also not well known.

FHY11 showed the features of low-level atmospheric circulation and OLR fields related to the ISO in Bangladesh for a limited area $\left(5-35^{\circ} \mathrm{N}, 65-115^{\circ} \mathrm{E}\right)$ over the South Asian monsoon domain. In this paper, we provide a detailed picture of the rainfall distribution in the submonthly-scale ISO in relation to topographical features over South Asia. We also present a broader picture of large-scale convection and three-dimensional atmospheric structures, focusing on intraseasonal linkage between the tropics and mid-latitudes.

Section 2 describes the datasets and analysis methods used in this study. The detailed topographic features and their dependent ISO signals around South Asia are presented in Sect. 3. Section 4 gives the spatiotemporal structure of large-scale atmospheric circulation and convection extending from the tropics to the mid-latitudes, related to the distinct submonthly-scale ISO around the Meghalaya (located in northeastern India near the Bangladesh border)-Bangladesh-coast of the western Myanmar region. The dynamics that are likely to cause this distinct ISO are discussed based on the observational evidence in Sect. 5. Finally, the results are summarized in Sect. 6.

\section{Data and methods}

We used the APHRODITE rainfall dataset to examine rainfall fluctuations and spatial distributions around South Asia from 1979 to 2007 (29 years). The APHRODITE dataset is a state-of-the-art daily precipitation dataset with high resolution $\left(0.25^{\circ} \times 0.25^{\circ}\right)$ grids for Asia covering the land only (Yatagai et al. 2009, 2012). The datasets are created primarily with data obtained from a dense raingauge observation network with orographic effects taken into account during interpolation. To support the rainfall distribution based on APHRODITE and further elucidate the detailed relationship between terrain features and rainfall distribution including over the ocean area, we also used TRMM PR 2A25 version 7 data (Iguchi et al. 2000) from 1998 to 2010 (13 years). We compiled the TRMM PR data into gridded data with a resolution of $0.05^{\circ} \times 0.05^{\circ}$. We used the near-surface rain rate to examine the spatial distribution of rainfall. Rainfall frequency and intensity were also calculated using the near-surface rain rate. Daily interpolated outgoing longwave radiation (OLR) data on a $2.5^{\circ}$ latitude-longitude grid were used as a proxy for largescale convective activity from 1979 to 2010 (32 years) (Liebmann and Smith 1996). We also used the Japanese 25-year (1979-2004) reanalysis (JRA25)/Japan Meteorological Agency (JMA) Climate Data Assimilation system (JCDAS) datasets on a $1.25^{\circ}$ latitude-longitude grid to explore large-scale atmospheric circulation associated with the rainfall ISO (Onogi et al. 2007). The JRA25 dataset covers the period from 1979 to 2004 . Since 2005 to the present, JCDAS has provided data of the same quality as JRA25 using the same assimilation system as JRA25. Thus, we can conduct a diagnostic study with a homogeneous dataset covering the period from 1979 to the present. These reanalysis data with high spatial resolution can provide detailed information on atmospheric structures in the ISO evolution around South Asia, which cannot be discerned in coarse reanalysis data. The dataset variables included horizontal wind ( $\mathrm{u}$ and $\mathrm{v}$ ), specific humidity (q) and streamfunction $(\psi)$. Vertically integrated water vapor flux from the surface to $100 \mathrm{hPa}$ was also calculated. The data were daily-averaged before analysis.

Most of the data processing and analysis methods employed here are similar to those used by FHY11. Daily anomalies of rainfall, OLR, and the reanalysis data were computed by subtracting the first three harmonics of the annual cycle (about 120 days) for each year. To extract the submonthly (7-25 days) variability signal, a Lanczos bandpass filter was applied to the detrended daily anomalies (Duchon 1979). The power spectrum of the unfiltered detrended rainfall time series for the 29-year APHRODITE rainfall around Bangladesh had dominant power in the submonthly range with a peak at $\sim 14$ days (not shown), similar to the findings of FHY11 (Fig. 3a of FHY11). Hence we used the frequency range (i.e., 7-25 days) for time filtering.

A composite method similar to that of FHY11 was used to describe the mean behavior of the ISO. We chose a reference time series of APHRODITE precipitation averaged over the area including a part of northeastern India, Bangladesh, and the coast of western Myanmar $\left(20-26^{\circ} \mathrm{N}\right.$, $\left.88-93^{\circ} \mathrm{E}\right)$, where submonthly signals are strongest in South Asia (Fig. 3b, c). On the basis of the 7-25-day rainfall anomalies, positive and negative extremes that exceeded the 29-summer climatological 1.0 standard deviation $\left(\sim 7.5 \mathrm{~mm} \mathrm{day}^{-1}\right)$ were selected as active and break peaks for the composites in atmospheric circulation, APHRODITE precipitation, and OLR fields. In total, 110 peak active and 105 peak break days were identified during the 29 summer monsoon seasons (June to August; JJA). Daily lag composites of various fields were also constructed relative to these peak active days, denoted by day 0 . The statistical significance of the composite differences and anomaly fields at each grid point was estimated using 

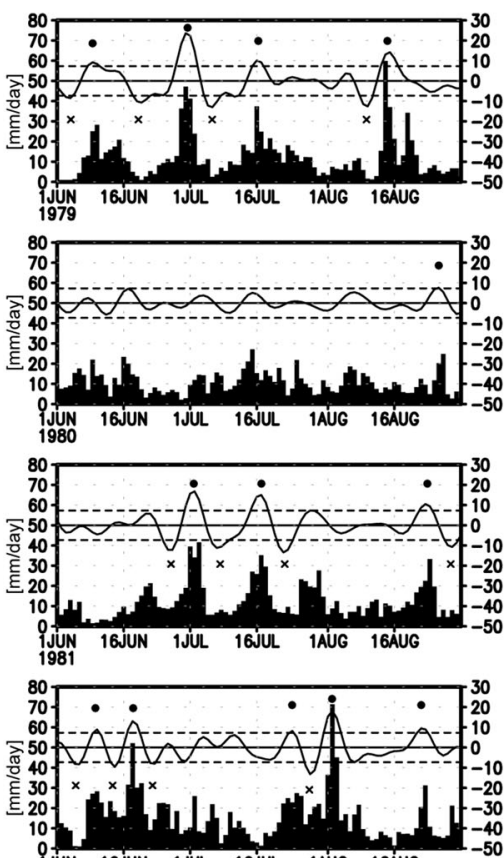
1JUN 1GJUN 1JUL 16UUL 1AUG 16AUG
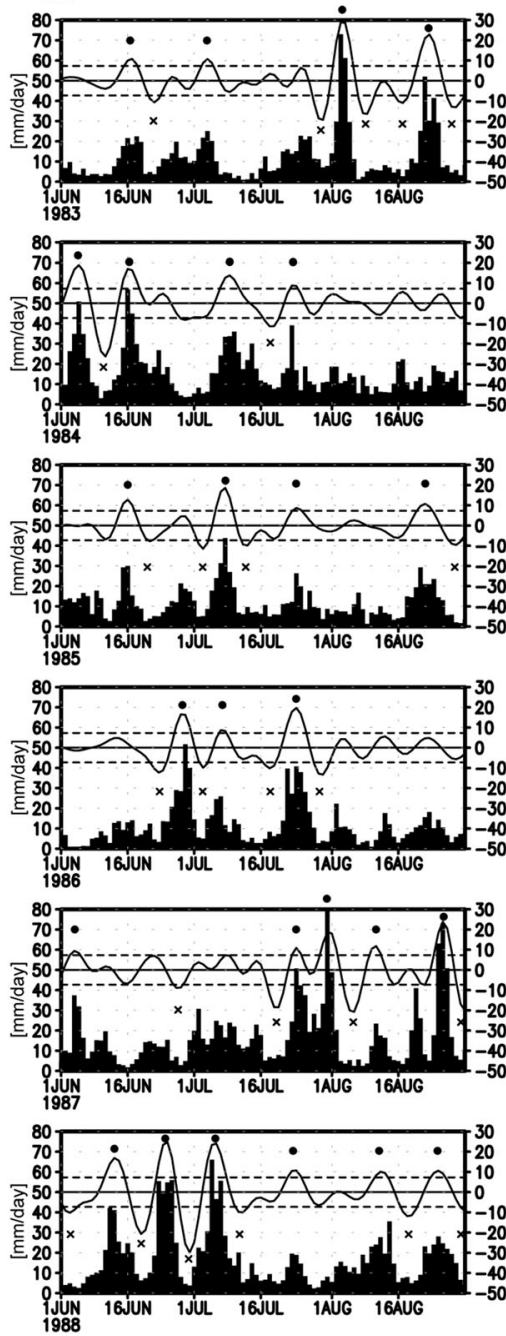
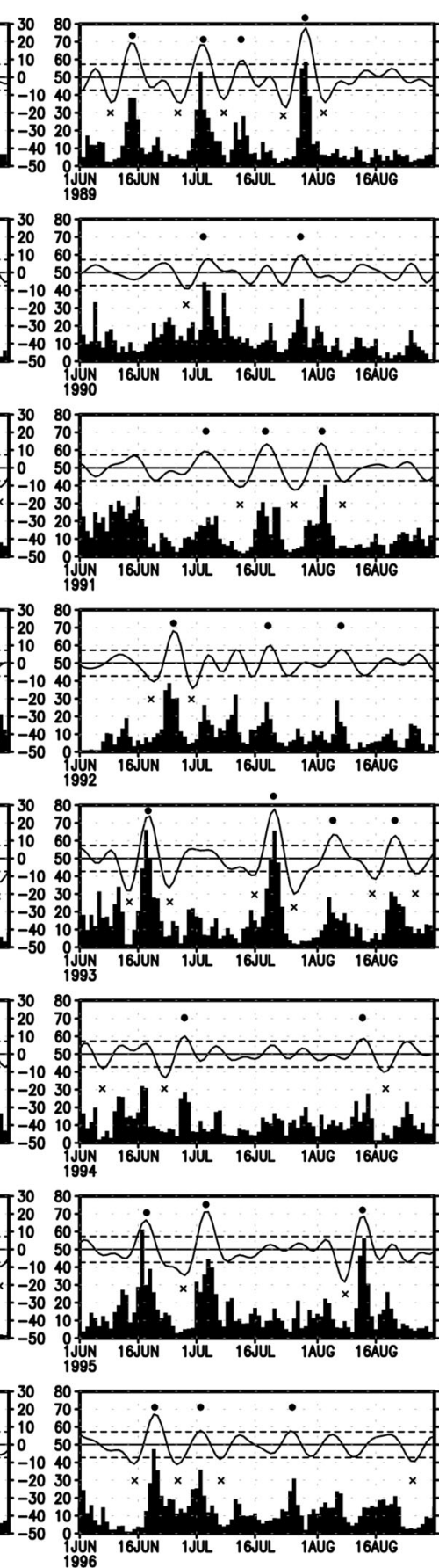

19
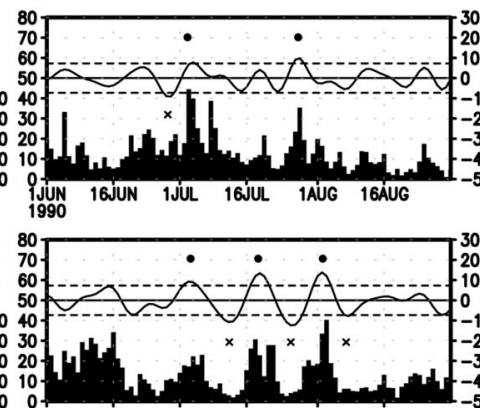

1JUN 16JUN 1JUL 16UUL 1AUG 16AUG
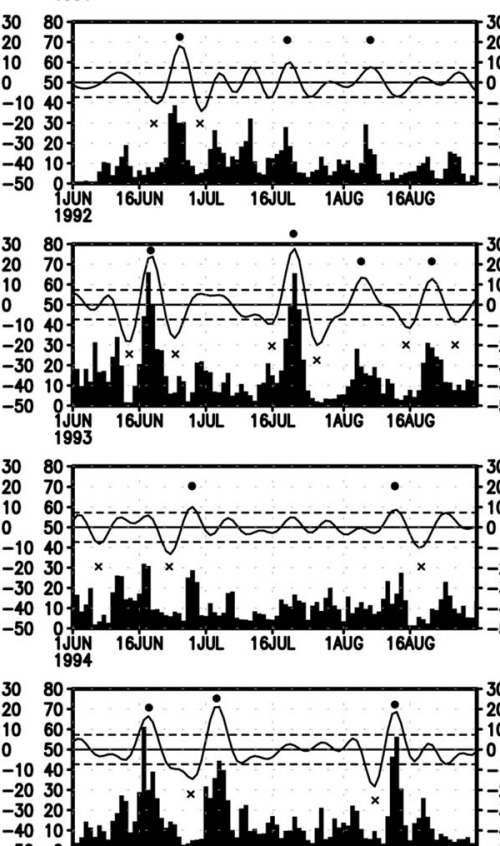

PJUN 16JUN 1JUL 16JUL TAUG 16AUG
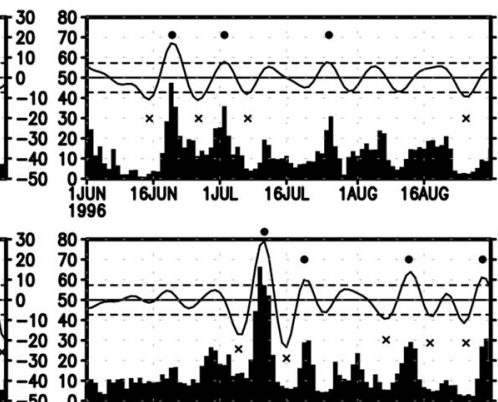

OJUN 16JUN 1JUL 16UUL IAUG 16AUG

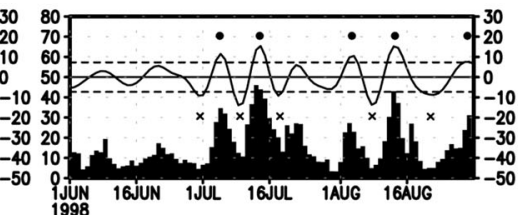

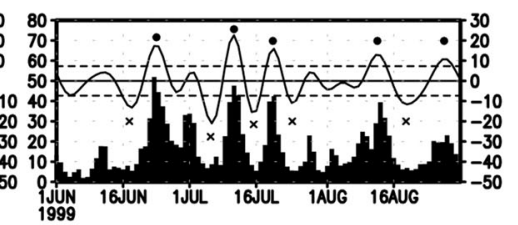
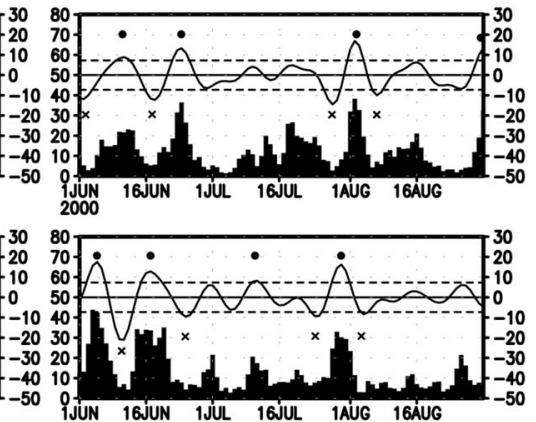

1JUN 16JUN 1JUL 16JUL 1AUG 16AUG

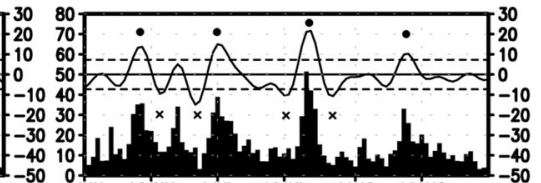

1JUN 16JUN 1JUL 16UUL IAUG 16AUG
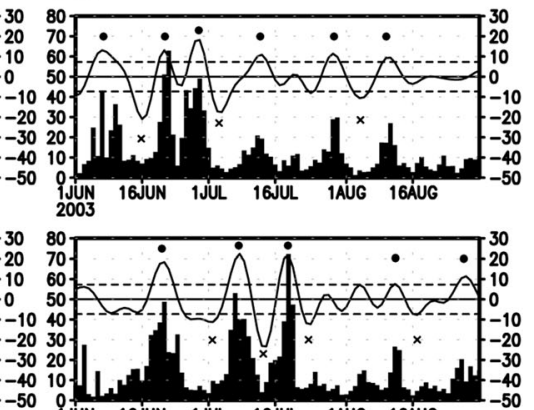

PJJUN 16JUN 1JUL 16JUL 1AUG 16AUG
2004

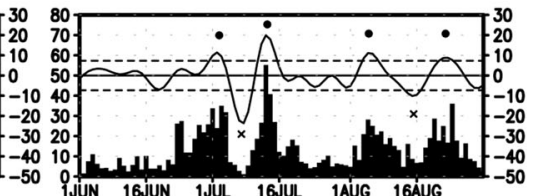

1JUN 16JUN 1JUL 16JUL IAUG 16AUG
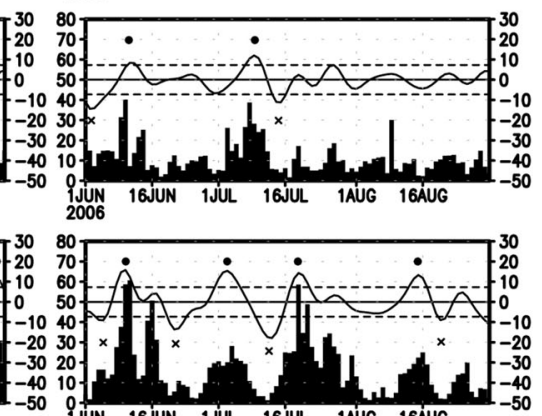
४Fig. 2 Time series of rainfall averaged over the rectangular domain of $20^{\circ}-26^{\circ} \mathrm{N}, 88^{\circ}-93^{\circ} \mathrm{E}$ from 1979 to 2007 (black bars; left axis) and 7-25-day filtered rainfall (solid line; right axis). Dotted lines in each figure denote the 29-summers (JJA) climatological 1.0 standard deviation. Closed circles and cross marks near the filtered time series denote selected active and break peaks, respectively

Student's $t$ test. In the composite of TRMM-PR data, a $7-25$ day filtered area-averaged $\left(20-25^{\circ} \mathrm{N}, 88.5-92.5^{\circ} \mathrm{E}\right)$ OLR time series was used as a reference because the APHRODITE rainfall dataset ended at 2007. The correlation value between the reference time series of the APHRODITE dataset and the filtered OLR anomalies for the 29 summers (2,668 days) was $\sim 0.7$ in Bangladesh (figure not shown), which exceeded the $99 \%$ significance level. Therefore, it is reasonable to use the filtered OLR anomalies instead of APHRODITE rainfall anomalies for the composites of TRMM-PR. We confirmed that nearly identical distributions of OLR and atmospheric circulation fields were seen in the composites using both of the references. The method used to choose active and break peaks was similar to that used for APHRODITE rainfall, and 76 peak active and 67 peak break days were identified during the 13 summer monsoon seasons. In order to present a robust rainfall distribution associated with active and break phases of the ISO from TRMM-PR, we used three consecutive days centered on the peak days as active phase and break phases for the composites. In short, totals of 228 active days and 201 break days could be used to make the composites. Some previous studies successfully showed clear composite differences in rainfall distribution associated with active and break phases related to ISOs using TRMM-PR data (Singh and Nakamura 2010; Shrestha et al. 2012).

\section{Regional-scale rainfall distribution related to submonthly-scale ISO and topography}

\subsection{Climatological features}

Our target area in this study is around northeastern India, Bangladesh, and the coast of western Myanmar (Fig. 1). The Gangetic Plain is characterized by an area of east-west elongated flat lowland, south of the Himalayas/TP. The eastern part of the Gangetic Plain faces the Bay of Bengal, from which southerly moist winds can intrude into the plain. In the easternmost part of the Gangetic Plain, the Meghalaya Plateau stands at $\sim 2,000 \mathrm{~m}$ above sea level extending east to west, and the Chittagong Hill Tracts and the Arakan Mountains extend north to south. These regional-scale topographical features enhance the localized area of high rainfall in the windward regions (Fig. 3a). Previous papers have noted the localized high rainfall areas arising from regional-scale topography in a climatological sense using high-resolution TRMM-PR data (Hirose et al. 2008; Nesbitt and Anders 2009; Romatschke and Houze 2011; Biasutti et al. 2012).

Figure 2 presents the daily rainfall time series averaged over the region $20-26^{\circ} \mathrm{N}, 88-93^{\circ} \mathrm{E}$ for the 29 summers. A distinct submonthly-scale ISO appears in almost all of the 29 summers even in the unfiltered time series. The mean spectrum for the 29-year rainfall time series shows that a pronounced peak appears at a period of $\sim 14$ days that exceeds the $95 \%$ confidence level. A peak around the 30-40-day period can also be found but is not statistically significant (not shown). The 7-25-day filtered time series is also shown in Fig. 2. The active and break peaks of the filtered time series represent those of the unfiltered time series well. Thus, these results justify our choice of frequency range for time filtering.

Figure $3 \mathrm{~b}$ presents the percentage of the total variance of rainfall explained by the 7- to 25-day band in summer. Localized high values $(\geq 40 \%)$ are observed around the Meghalaya Plateau, the Chittagong Hill Tracts, and the coast of western Myanmar. Furthermore, the area with values greater than $35 \%$ covers almost all of Bangladesh. Thus, the Meghalaya-Bangladesh-coast of western Myanmar (hereafter abbreviated to MBWM) region is the most dominant area of the submonthly-scale ISO among the onshore Asian monsoon regions. High percentage values extend westward from the MBWM along the Gangetic Plain. Relatively high values are also observed around southeastern China, the east coast of the Indochina Peninsula, the southern TP, and the Western Ghats. The percentage of total variance explained by 7-25 day OLR anomalies reveals a comprehensive picture of the submonthly-scale ISO, including regions over the oceans (Fig. 3c), although a regional-scale structure cannot be detected because of the coarse grid of the OLR data. Large submonthly variances appear over the Bay of Bengal and South China Sea, while large percentages of variance appear around the MBWM, northeastern coast of Vietnam, and the western TP. The highly localized strong signals of the submonthly-scale ISO suggest the presence of unique dynamics for enhancing the submonthly-scale ISO preferentially around the MBWM.

Low-level wind variation is an important element needed to induce rainfall fluctuation. To indicate the preferred locations of low-level horizontal wind variation, $925-\mathrm{hPa}$ perturbation kinetic energy (PKE) on the 7-25-day timescale is shown in Fig. 3d. PKE is defined by

$\mathrm{PKE}=\frac{1}{2}\left(\overline{u^{\prime 2}+v^{\prime 2}}\right)$

where the overbar denotes the time mean, and $\mathrm{u}^{\prime}$ and $\mathrm{v}^{\prime}$ are the 7-25 day filtered zonal and meridional winds, 
Fig. 3 Climatological

(1979-2007) seasonal (JuneAugust) mean distribution of a rainfall from APHRODITE datasets, $\mathbf{b}$ the percentage of the total variance (with the seasonal cycle of rainfall removed) explained by the 7-25-day band obtained from APHRODITE. Only areas where climatological seasonal mean rainfall is more than $1.5 \mathrm{~mm}$ day $^{-1}$ are shaded, c the variance of 7-25-day filtered OLR (solid line) and the percentage of the total variance (with the seasonal cycle of OLR removed) explained by the 7-25-day band (shading), and d 7-25-day PKE at $925 \mathrm{hPa}$. a-c The topographic contour for $3,000 \mathrm{~m}$ is shown as a thick solid line. $\mathbf{d}$ The topographic contours for 1,500 and $3,000 \mathrm{~m}$ are shown as dashed lines (a) Precipitation (APHRODITE)

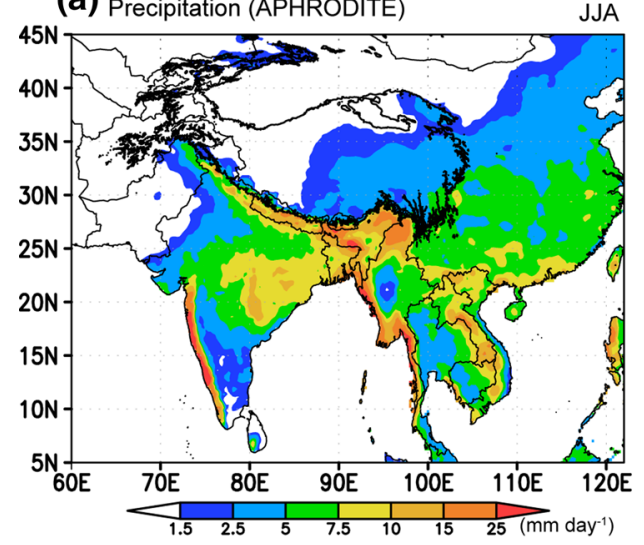

(c) Variance of 7-25-day OLR and its explained variance

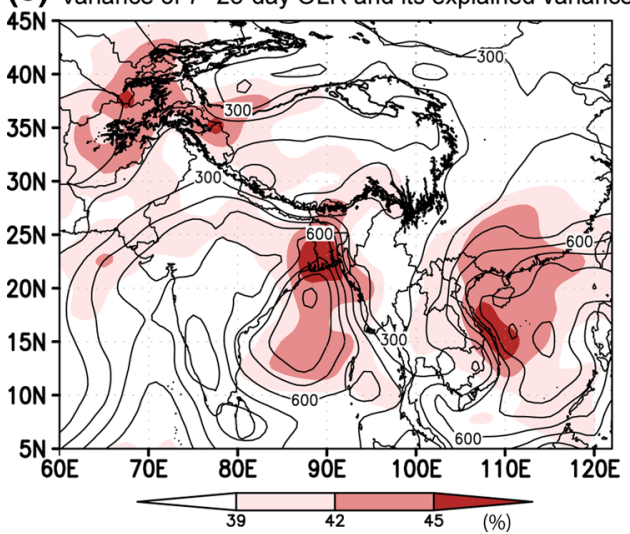

(b) Percent variance explained by 7-25-day band JJA

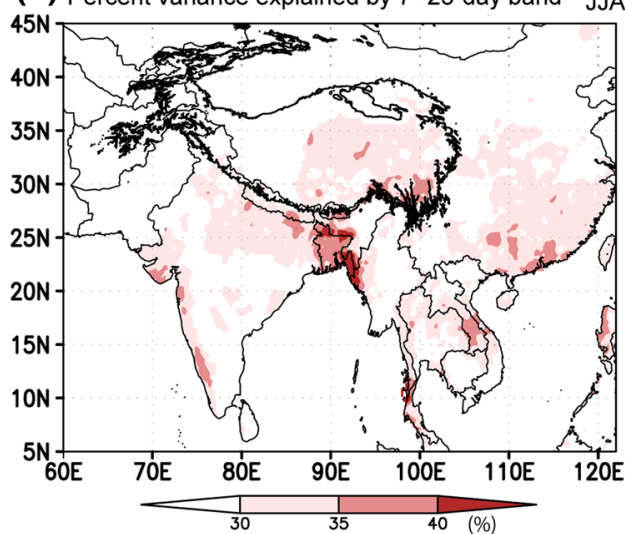

(d) 7-25-day 925-hPa PKE

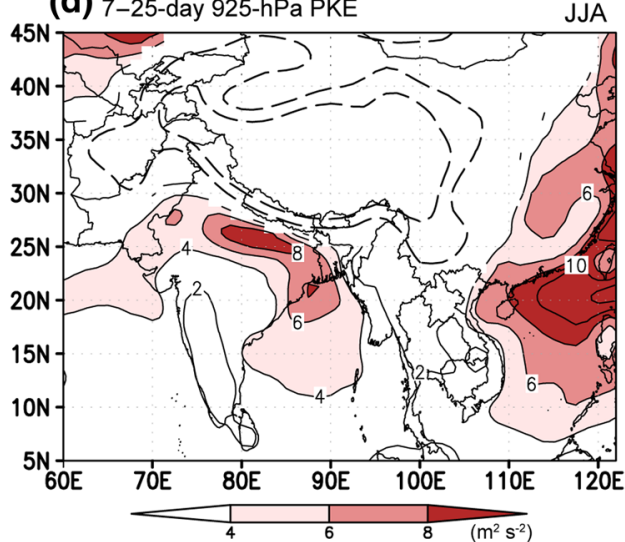

respectively, following the method used in Matthews and Kiladis (1999). A local maximum extends zonally along the Gangetic Plain, south of the TP. The zonal wind perturbation $\left(u^{\prime}\right)$ mainly contributes to form the PKE maximum over the plain. The enhanced zonal wind variation provides a favorable environment for distinct submonthlyscale ISO in rainfall around the MBWM.

\subsection{Detailed rainfall distribution and its time evolution}

To show in detail the spatial distribution of rainfall and its relationship with topography, the rainfall distribution and integrated water vapor flux vectors in active and break phases of the MBWM are shown in Fig. 4. In the peak active phase (Fig. 4a), high rainfall areas spread around the MBWM, the southern slope of Himalayas, and the Western Ghats. Westerly/southwesterly moisture flow prevails around the MBWM. Note that a localized center of cyclonic relative vorticity appears at $925 \mathrm{hPa}$ over western Bangladesh. Therefore, wind components normal to the windward slopes of the Meghalaya Plateau, the Chittagong Hill Tracts, and the western coast of Myanmar are enhanced, and then high rainfall $\left(\geq 50 \mathrm{~mm} \mathrm{day}^{-1}\right)$ is observed over these regions probably due to orographic lifting of moist air. Relatively high rainfall $\left(\geq 20 \mathrm{~mm} \mathrm{day}^{-1}\right.$ ) is also observed in the lowland area of the MBWM away from the regional-scale mountains, resulting from frictional convergence in the boundary layer under strong low-level cyclonic circulation. In contrast, the direction of moisture flow changes such that easterly/ southeasterly flow prevails along the Gangetic Plain in the peak break phase (Fig. 4b). The easterly/southeasterly flow can travel along the Gangetic Plain from northwestern Bangladesh without orographic barriers. Thus, precipitation decreases significantly along the Gangetic Plain on peak break days. The composite difference highlights these differences mentioned above (Fig. 4c). A significant positive difference in rainfall also appears along the southern slope of the Himalayas and the southeastern TP, where significant moisture flux vectors are also shown. Figure $4 \mathrm{~d}-\mathrm{f}$ from TRMM-PR datasets highlight and reinforce the relationship between the locations of rainfall maxima and regional-scale topographic features including over the ocean. The composites from TRMM-PR can capture overall features of those from APHRODITE datasets well, although the absolute values of rainfall in TRMM-PR are smaller than those in APHRODITE over land. In the active phase (Fig. 4d), the southern slope of the Meghalaya Plateau has a localized precipitation maximum. In contrast, around the coast of western Myanmar, the high rainfall 
Fig. 4 Composites of a rainfall (APHRODITE) and vertically integrated (from surface to $100 \mathrm{hPa}$ ) water vapor flux vectors in the peak active phase of the 7-25-day ISO over the MBWM. The contours of 925-hPa positive (i.e., cyclonic) vorticity more than $2.5 \times 10^{-5} \mathrm{~s}^{-1}$ are shown by dotted lines. The contour interval of vorticity is $0.5 \times 10^{-5} \mathrm{~s}^{-1}$. The unit of water vapor flux is $\mathrm{kg} \mathrm{m}^{-1} \mathrm{~s}^{-1}$. The topographic contours of 500 and 3,000 $\mathrm{m}$ are also shown as thin solid lines. $\mathbf{b}$ As in $\mathbf{a}$, but for peak break phase. c As in a but for the difference between peak active and peak break phases. The thick solid line indicates areas with $99 \%$ statistically significant difference in rainfall. Only water vapor flux vectors that show $99 \%$ statistically significant difference are plotted. d Composite of rainfall obtained from TRMM-PR in the active phase. e As in $\mathbf{d}$, but for the break phase. $\mathbf{f}$ As in $\mathbf{d}$, but for the difference between the active and break phases (a) Active phase

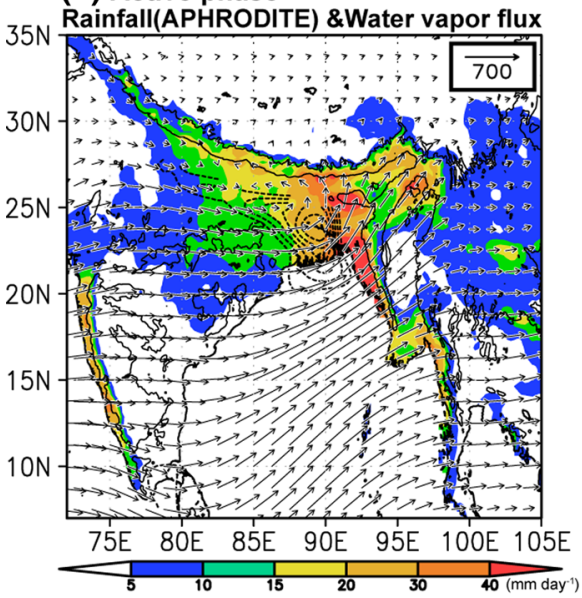

(b) Break phase
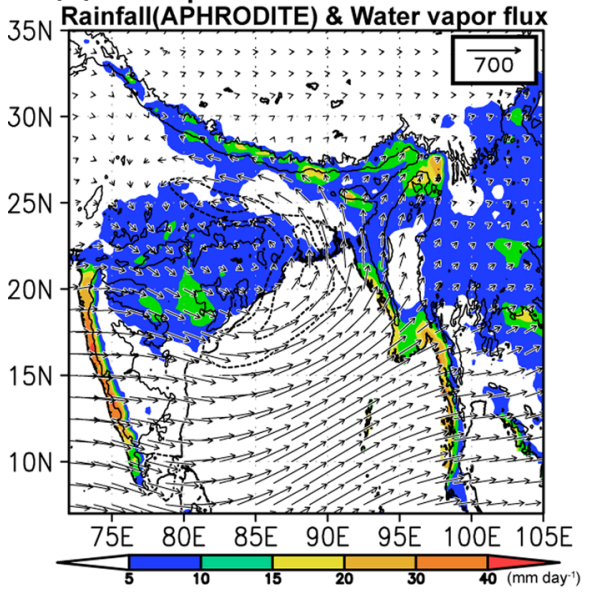

(c) Active - Break 35N Rainfall(APHRODITE) \& Water vapor flux

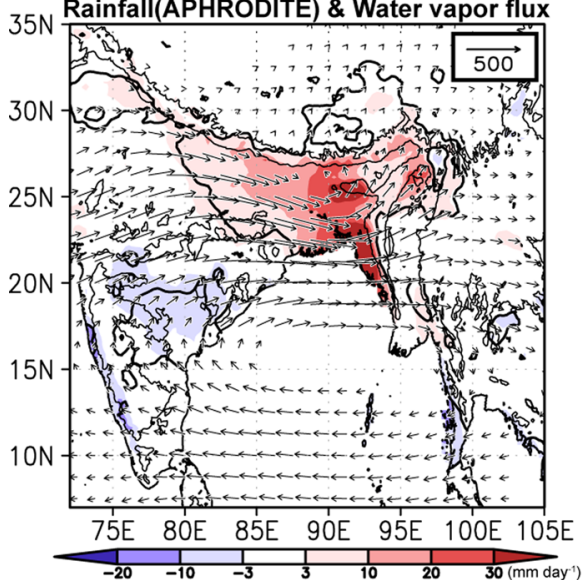

(d) Active phase

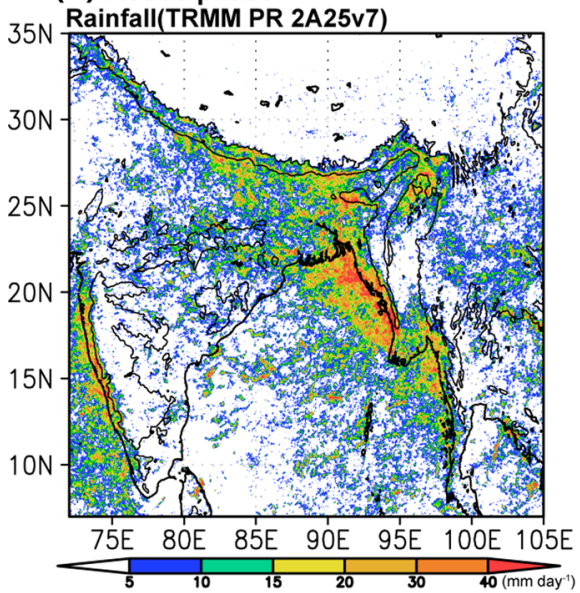

(e) Break phase

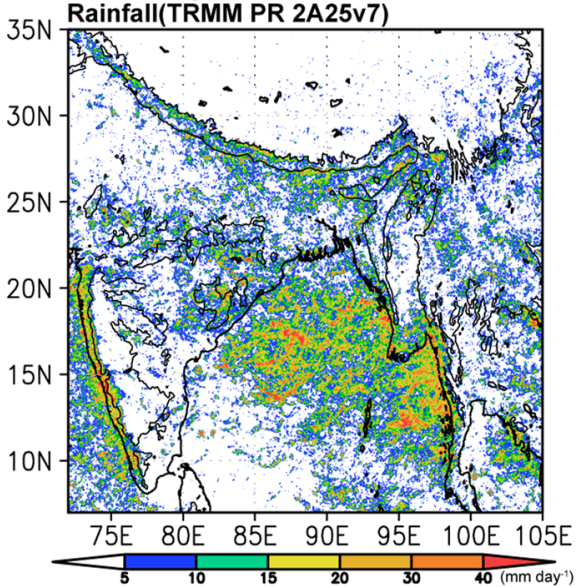

(f) Active - Break

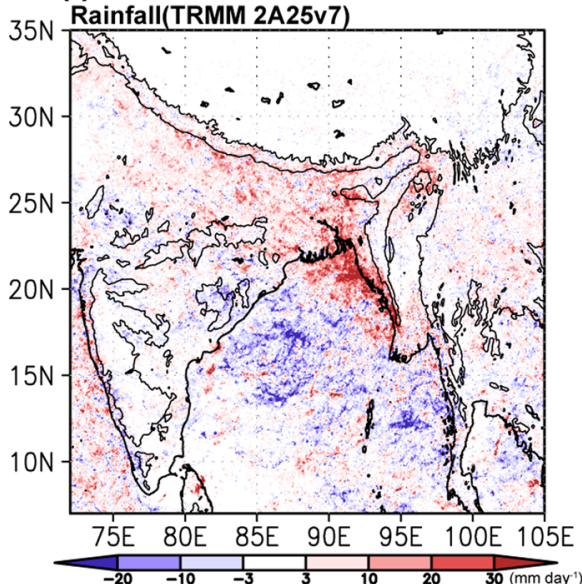

area extends to the Bay of Bengal with highest rainfall along the coastline. The break phase is characterized by the increase in rainfall over the Bay of Bengal and central India. The scattered high rainfall area spreads widely over the Bay of Bengal (Fig. 4e). The difference shows a northsouth shift in the high rainfall area associated with the submonthly-scale ISO (Fig. 4f).
Figure 5 shows the vertical latitude/longitude sections of horizontal wind speed, specific humidity, and horizontal water vapor flux. Rainfall, rain frequency, and rain intensity derived from TRMM-PR are also displayed in this figure. Selected latitudes and longitudes include high rainfall areas over the Meghalaya Plateau (Fig. 5a, b, e, f) and the coast ranging from southeastern Bangladesh to 
Fig. 5 a Vertical-latitude section of horizontal wind speed ( $\mathrm{m} \mathrm{s}^{-1}$; color shadings), horizontal water vapor flux vectors $\left(\mathrm{m} \mathrm{s}^{-1} \mathrm{~g} \mathrm{~kg}^{-1}\right)$, and specific humidity ( $\mathrm{q} \mathrm{kg}^{-1}$; black contours) averaged between $91^{\circ}$ and $92^{\circ} \mathrm{E}$ in the peak active phase over the MBWM. Horizontal wind speed of more than $6 \mathrm{~m} \mathrm{~s}^{-1}$ is shaded. The contour interval for horizontal wind speed is $1 \mathrm{~m} \mathrm{~s}^{-1}$ (white contours). The unit of water vapor flux is $\mathrm{g} \mathrm{g}^{-1} \mathrm{~m} \mathrm{~s}^{-1}$. Black shading denotes the topography; the peak from $25^{\circ}$ to $26^{\circ} \mathrm{N}$ is on the Meghalaya Plateau. b Rainfall (mm day ${ }^{-1}$; black bar; left axis), rain frequency $(\%$; red line; left axis), and rain intensity $\left(\mathrm{mm} \mathrm{h}^{-1}\right.$; green line; right axis) averaged between $25^{\circ}$ and $26^{\circ} \mathrm{N}$ in the active phase from TRMM-PR. c As in a but for vertical longitude section averaged between $20.5^{\circ}$ and $21.5^{\circ} \mathrm{N}$. The peak around $94^{\circ} \mathrm{E}$ is over the Arakan Mountains; the coastline is located at $\sim 92^{\circ} \mathrm{E}$, and the Chittagong Hill Tracts is in between. d As in b but for averaged between $20.5^{\circ}$ and $21.5^{\circ} \mathrm{N}$. e, f As in a and $\mathbf{b}$ but for the peak break phase in the MBWM. g, h As in c and $\mathbf{d}$ but for the break phase (a) WVF, q \& wind speed 91E-92E Active

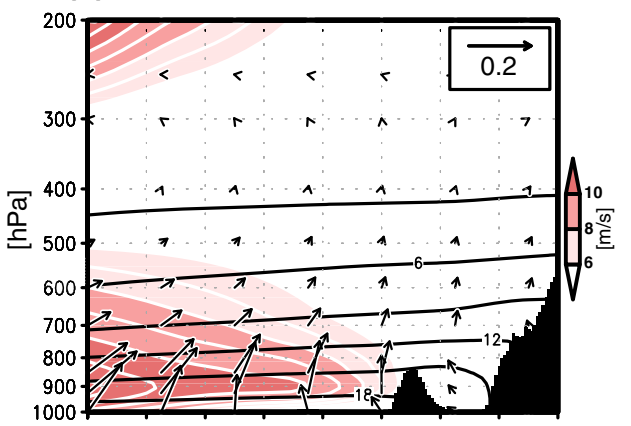

(b) Rainfall, rain frequency and intensity

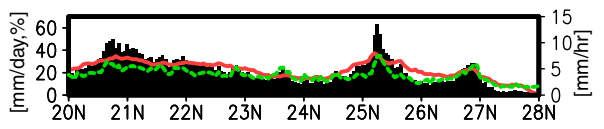

(c) WVF, q \& wind speed $20.5 \mathrm{~N}-21.5 \mathrm{~N}$ Active

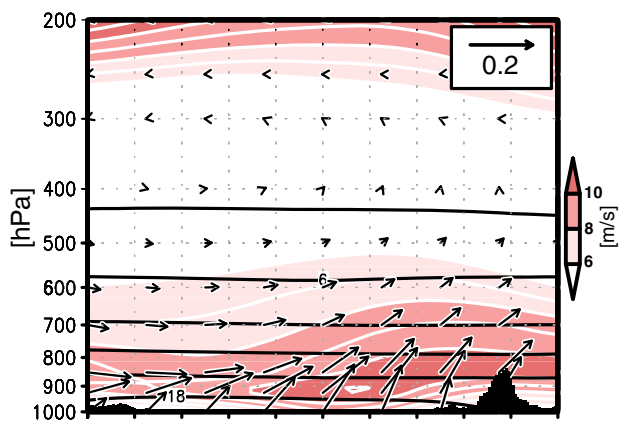

(d) Rainfall, rain frequency and intensity

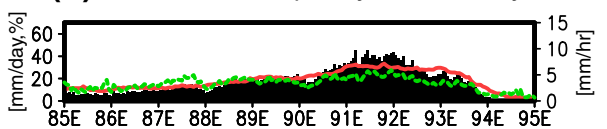

(e) WVF, q \& wind speed 91E-92E Break

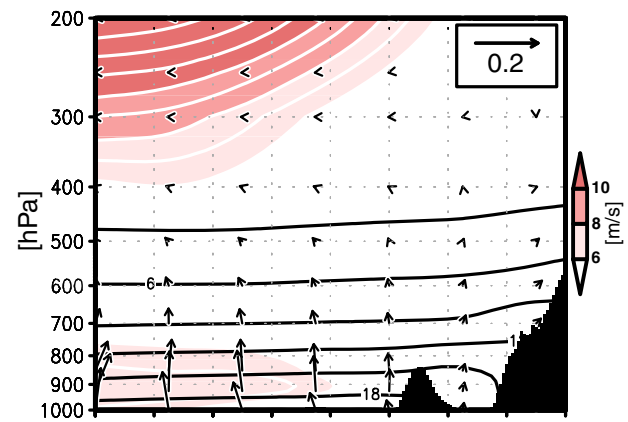

(f) Rainfall, rain frequency and intensity

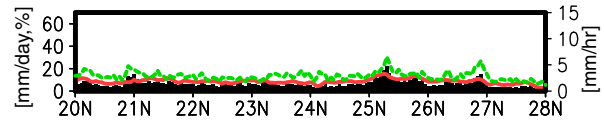

(g) WVF,q \& wind speed $20.5 \mathrm{~N}-21.5 \mathrm{~N}$ Break

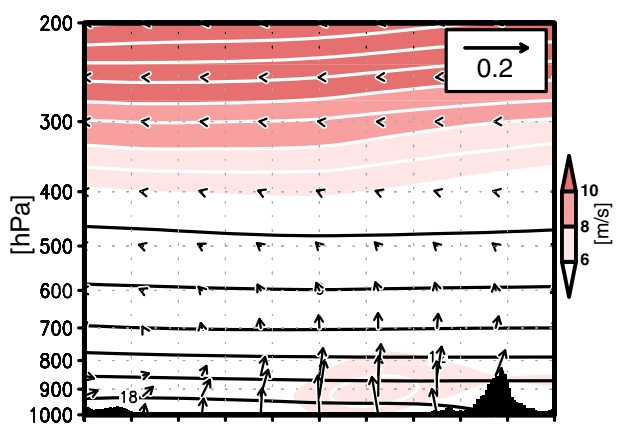

(h) Rainfall, rain frequency and intensity

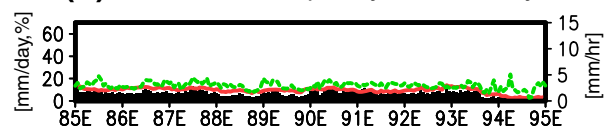

western Myanmar, respectively, where the Chittagong Hill Tracts and Arakan mountains are located to the east of the coastline (Fig. 5c, d, g, h). In the active phase, high rainfall appears around $25-26^{\circ} \mathrm{N}$ and its peak ( $\geq 60 \mathrm{~mm} \mathrm{day}^{-1}$ ) corresponds only to the southern slope of the Meghalaya Plateau (Fig. 5a, b). The rainfall is characterized by high rainfall frequency $(\sim 40 \%)$ and relatively high rainfall intensity $\left(\sim 7 \mathrm{~mm} \mathrm{~h}^{-1}\right)$ (Fig. 5b). The rainfall peak around $21^{\circ} \mathrm{N}$ is a part of the rainfall distribution near the coast from southeastern Bangladesh to western Myanmar. A strong and humid low-level southwesterly/southerly flows toward the Meghalaya Plateau with its maximum wind speed around $900 \mathrm{hPa}$. In contrast, the low-level wind speed toward the plateau in the break phase becomes significantly weakened (Fig. 5e). Rainfall frequency reduces greatly $(\leq 20 \%)$, and in turn the rainfall amount decreases around the Meghalaya Plateau (Fig. 4f). The difference in the low-level specific humidity between active and break phases is not so large; the value averaged from 1,000 to
$850 \mathrm{hPa}$ at the same longitudes is less than $0.5 \mathrm{~g} \mathrm{~kg}^{-1}$. In short, the change in the low-level wind speed mainly contributes to the large difference in water vapor flux between the active and break phases. The vertical stratification in the peak active and break days (defined as the vertical difference of equivalent potential temperature between $1,000 \mathrm{hPa}$ and $600 \mathrm{hPa}$ ) is 15.2 and $16.3 \mathrm{~K}$, respectively, at $22.5^{\circ} \mathrm{N}, 90^{\circ} \mathrm{E}$. Thus, low-level atmosphere exhibits slightly stronger convective instability on peak break days than on peak active days. Recently, Sato (2013) pointed out that the intensity of southerly/southwesterly low-level wind around $900 \mathrm{hPa}$ is a crucial factor in heavy precipitation around the Meghalaya Plateau during the active period of submonthly-scale ISO because stronger low-level wind is sufficient to overcome the vertical stratification barrier and can reach the lifting condensation level. At latitudes of $20.5-21.5^{\circ} \mathrm{N}$, a strong southwesterly low-level wind is dominant over the head of the Bay of Bengal in the active phase (Fig. 5c), whereas a weak 
southerly is observed in the break phase (Fig. $5 \mathrm{~g}$ ), indicating that the wind component of the direction normal to the coastline and mountains is enhanced in the active phase and significantly decreases in the break phase. The coastline under examination here is located at $\sim 92^{\circ} \mathrm{E}$, and the Arakan Mountains are found around $94^{\circ} \mathrm{E}$. The Chittagong Hill Tracts are in between. In the active phase, the lowlevel wind speed decreases eastward, indicative of the lowlevel convergence around the coast (Fig. 5c). An area of rainfall of more than $20 \mathrm{~mm}^{\text {day }}{ }^{-1}$ spreads from 90.5 to $93.8^{\circ} \mathrm{E}$ with its peak $\left(\geq 40 \mathrm{~mm} \mathrm{day}^{-1}\right)$ over the coastline (i.e., $\sim 92^{\circ} \mathrm{E}$ ), which is broader than that around the Meghalaya Plateau. In this region, the high rainfall is a result of both high rainfall frequency and intensity (Fig. 5d). A sharp decrease in rainfall appears on the leeward side of the Arakan Mountains (i.e., the rain shadow effect of mountains). In the break phase, both rainfall frequency and intensity become weakened, and in turn the rainfall amount decreases greatly (Fig. 5h).

To illustrate the phase relationship between rainfall and topographical features, Fig. 6 presents daily-lag composites of APHRODITE rainfall and vertically integrated moisture flux vectors from day -5 to day 0 . Active rainfall peaks over MBWM are referred to as day 0 phases. The evolution from day -5 to day 0 nearly completes a half-cycle because the pattern at day 0 is similar to that at day -5 , with opposite signs. The next life cycle is almost a mirror image of the aforementioned life cycle. At day -5 , a negative rainfall anomaly extends over the MBWM with minima in the southern Meghalaya Plateau and the coastal areas of southeastern Bangladesh and western Myanmar. Southeasterly/ easterly moisture flux anomalies prevail along the Gangetic Plain. In contrast, a positive rainfall anomaly appears over central India where cyclonic circulation is observed. After day -3 , an anti-cyclonic circulation anomaly moves westward from the Indochina Peninsula to the Bay of Bengal along $\sim 15 \mathrm{~N}^{\circ}$. Southerly/southwesterly humid flow begins to become enhanced in the MBWM, and in turn the rainfall anomaly changes sign quickly from negative to positive between day -3 and day -2 . By day 0 , the anticyclonic circulation moves farther westward and reaches at $90^{\circ} \mathrm{E}$ over the Bay of Bengal. Then, the westerly/southwesterly moisture current is further enhanced over the MBWM. Wind components toward the windward slopes of the Meghalaya Plateau, the Chittagong Hill Tracts and the coast of western Myanmar reach a maximum. The time sequence reveals that the areas of large rainfall anomaly around the MBWM remain stationary, although the anticyclonic circulation over the Bay of Bengal that brings the westerly anomaly leading to the active ISO phase moves westward. The stationary feature of the rainfall anomaly suggests that the topographical features are essential to enhance rainfall and anchor it at a fixed location in the MBWM.

\section{Large-scale atmospheric circulation and convection related to the submonthly-scale ISO}

\subsection{Three-dimensional structure of atmospheric} circulation in the active and break phases

In this subsection, we present the three-dimensional structure of large-scale atmospheric circulation and the distribution of convection with reference to the submonthly-scale rainfall ISO in the MBWM region to show a large-scale process that causes the distinct ISO in the whole Asian summer monsoon system. Figure 7 shows atmospheric circulation and OLR fields in the active and break phases. In the peak active phase, a trough (i.e., monsoon trough) deepens over the Gangetic Plain, and a center of convection is located over the MBWM where an $850 \mathrm{hPa}$ westerly/southwesterly prevails (Fig. 7c). The enhancement of the westerly/southwesterly corresponds to the northward extension of large-scale monsoon westerly flow. In the middle troposphere, the main axis of the westerly jet is located around $40^{\circ} \mathrm{N}$ (Fig. 7b). A deep trough is observed around the southern TP; a dominant westerly blows around the MBWM, similar to that in the low-level troposphere. Note that a part of the mid-latitude westerly intrudes into South Asia along the southwestern periphery of the TP, related to the deep trough. The westerly intrusion from mid-latitudes and the westerly over the MBWM are clearly observed in a layer from 700 up to $400 \mathrm{hPa}$ in the active phase (figure not shown). The upper-level troposphere is characterized by the Tibetan high and its center is located to the west of $80^{\circ} \mathrm{E}$ (Fig. 7a). A ridge is also observed from $40^{\circ}$ to $60^{\circ} \mathrm{E}$ along the Asian subtropical jet at $\sim 40^{\circ} \mathrm{N}$. In contrast, the monsoon trough shifts southward in the break phase, and the center of convection appears over the Bay of Bengal (Fig. 7f). The strong low-level westerly appears up to $20^{\circ} \mathrm{N}$, while a weak easterly is observed over the MBWM. In the midtroposphere, there is a remarkable easterly over the MBWM south of the TP (Fig. 7e). The center of the upper-level Tibetan high is located around $25^{\circ} \mathrm{N}, 80^{\circ} \mathrm{E}$, and a stronger easterly is observed over the MBWM compared to the active phases (Fig. 7d). Thus, the easterly dominates in all layers of the troposphere over the MBWM.

Figure 8 highlights the difference in streamfunction $(\psi)$ and wind vectors between the active and break phases at each level. A striking feature in the $850 \mathrm{hPa}$ difference is a pair of anticyclonic anomalies along $85^{\circ} \mathrm{E}$ with centers around $15^{\circ} \mathrm{N}$ and $5^{\circ} \mathrm{S}$ (Fig. 8c). The other important difference is the cyclonic circulation anomaly around the TP. The strong low-level westerly wind, causing high rainfall around the MBWM, is induced by the pressure gradient between the anti-cyclonic anomaly and cyclonic anomaly 
Fig. 6 Composites of 7-25-day filtered rainfall (APHRODITE; shadings) and vertical integrated moisture flux anomalies from day -5 to day 0 based on 7-25-day rainfall variation in the MBWM. Day 0 corresponds to the active rainfall peak in the MBWM. Only $99 \%$ statistically significant areas of rainfall are shaded. Only $99 \%$ statistically significant moisture flux vectors are plotted. The topographic contours of 500 and $3,000 \mathrm{~m}$ are shown as thin solid lines (a) Day -5

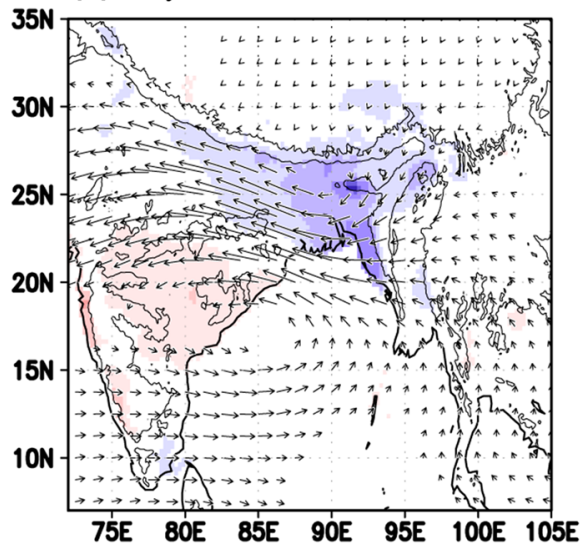

(b) Day -4

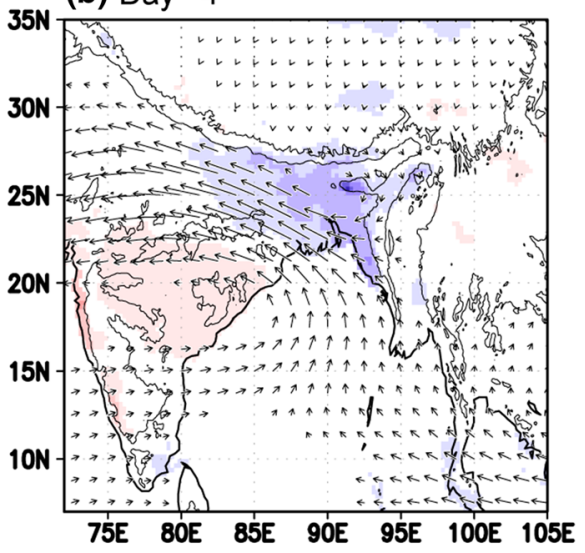

(c) Day -3

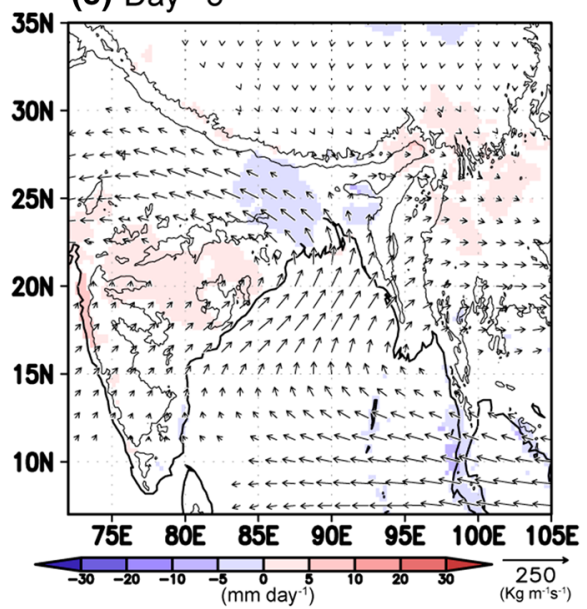

(d) Day -2

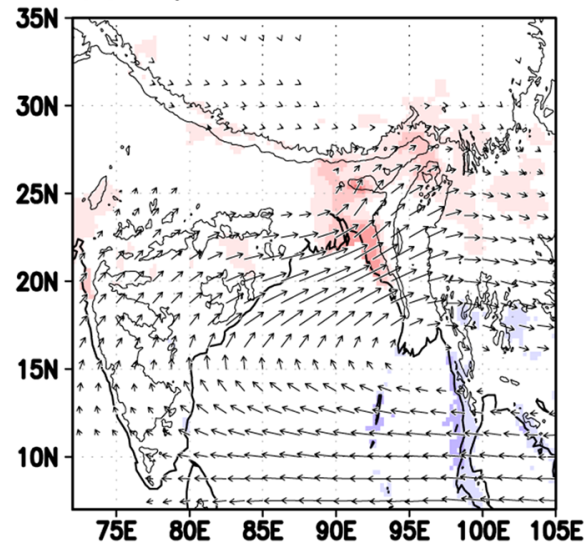

(e) Day -1

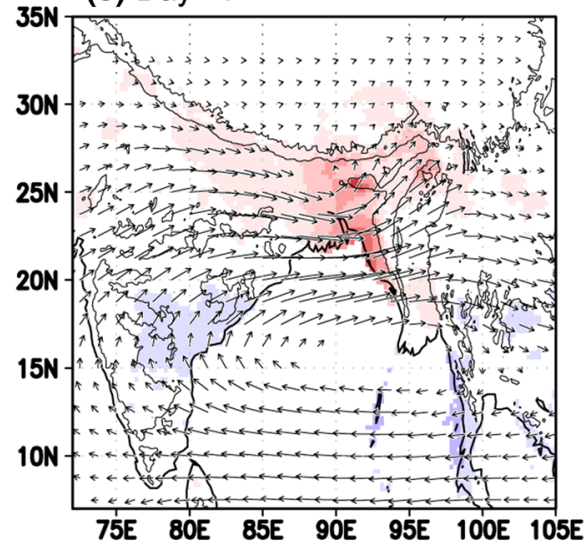

(f) Day 0 (peak active phase)

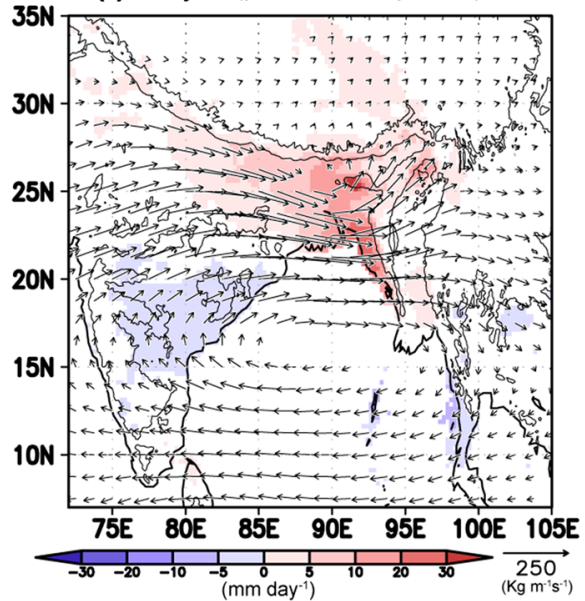

over the Bay of Bengal and areas to the south of TP, respectively. Thus, there is a north-south tripole structure of $\psi$ anomalies ranging from the tropics to the mid-latitudes. At $500 \mathrm{hPa}$, the horizontal structure of $\psi$ anomalies is nearly identical to that at $850 \mathrm{hPa}$ (Fig. 8b). A cyclonic anomaly becomes apparent over the TP. The north-south pressure gradient to the south of the TP results in the strong westerly anomalies from the western to southern periphery of the TP. At $200 \mathrm{hPa}$ (Fig. 8a), the anti-cyclonic anomaly is located centered on $35^{\circ} \mathrm{N}, 50^{\circ} \mathrm{E}$ and extends to the Indochina Peninsula zonally, as if to avoid the TP. A cyclonic circulation anomaly is observed over the TP on the downstream side of the center of the anticyclonic anomaly. 
Fig. 7 Composites of a $200 \mathrm{hPa}$ streamfunction $(\psi)$ and wind vectors in the peak active phase. The contour interval for $\psi$ is

$1.0 \times 10^{7} \mathrm{~m}^{2} \mathrm{~s}^{-1}$. Shading denotes areas at an altitude of more than $3,000 \mathrm{~m}$. b As in a but for $500 \mathrm{hPa}$. Shading denotes areas of westerly flow (i.e., $\mathrm{u}>0$ ). The contour interval for $\psi$ is

$2.0 \times 10^{6} \mathrm{~m}^{2} \mathrm{~s}^{-1}$. Topographic contour for $3,000 \mathrm{~m}$ is shown as a thick solid line. $\mathbf{c}$ As in $\mathbf{a}$, but for $850 \mathrm{hPa}$. OLR values $<220 \mathrm{Wm}^{-2}$ are shaded. The contour interval for $\psi$ is $3.0 \times 10^{6} \mathrm{~m}^{2} \mathrm{~s}^{-1}$. The topographic contour for $3,000 \mathrm{~m}$ is shown as a thick solid line. $\mathbf{d}-\mathbf{f}$ As in $\mathbf{a}-\mathbf{c}$ but for the peak break days (a) 200-hPa $\psi$ and u,v

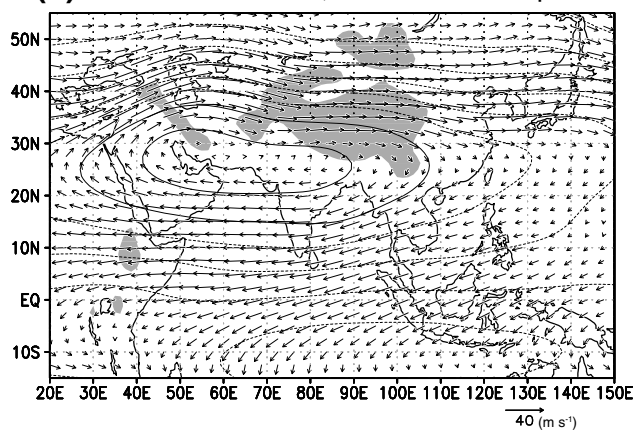

(b) 500-hPa $\psi$ and u,v

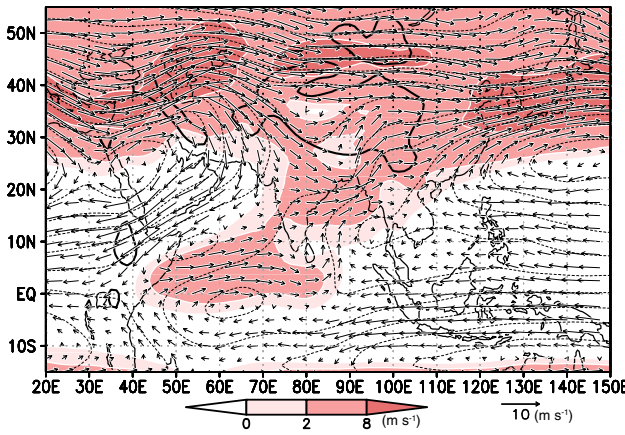

(c) $850-\mathrm{hPa} \psi$,u,v and OLR Active phase

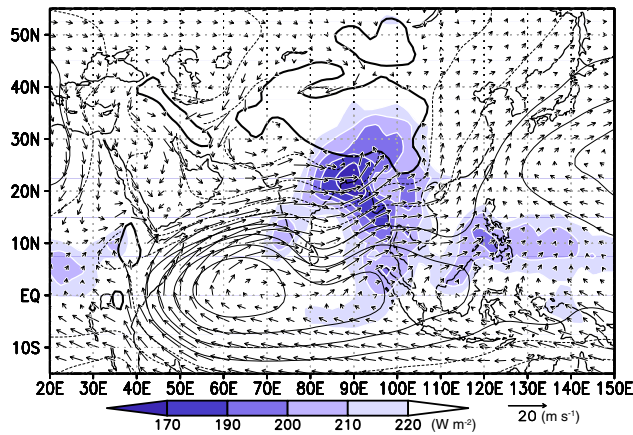

(d) 200-hPa $\psi$ and u,v

Break phase

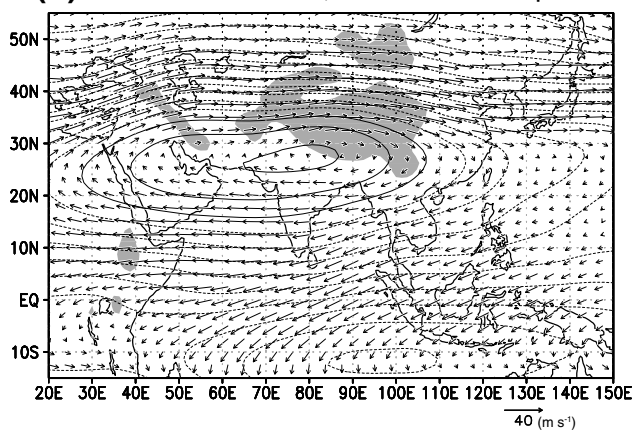

(e) 500-hPa $\psi$ and u,v

Break phase

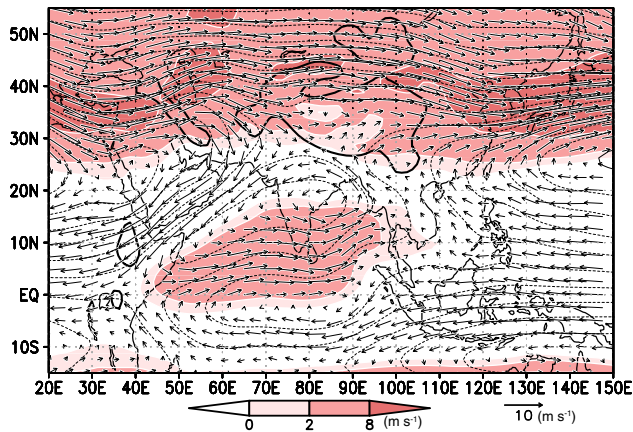

(f) 850-hPa $\psi, \mathrm{u}, \mathrm{v}$ and OLR Break phase

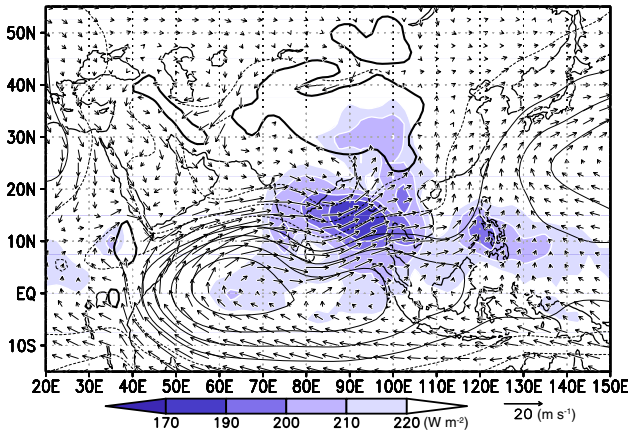

\subsection{Covariability between the tropics and mid-latitudes}

To show the extent of important anomalies linked to the submonthly-scale rainfall ISO over the MBWM, the variance in the composite life cycle from day -5 to day +5 is shown in Fig. 9. Almost all grids in the shaded area of Fig. 9 passed the $99 \%$ level of significance in the daily lag-composites at least once during the life cycle. The distribution of OLR variance exhibits the two preferred bands in convection along the latitudes of $15-30^{\circ} \mathrm{N}$ and $5-15^{\circ} \mathrm{N}$ from 50 to $140^{\circ} \mathrm{E}$ (Fig. 9d). The northern band extends from southern China to Pakistan via the MBWM, while the southern one extends from the western North Pacific/the South China Sea to western Indian Ocean through the Bay of Bengal. The $\psi$ variances reveal interesting signals that range widely from the tropics to the midlatitudes of the Northern Hemisphere across the Asian summer monsoon region (Fig. 9a-c). At $850 \mathrm{hPa}$, an east- west elongated area of large variance is evident along the latitudes of $10-20^{\circ} \mathrm{N}$ from 50 to $160^{\circ} \mathrm{E}$ (Fig. 9c). To the south of this area, along the latitudinal band from $\sim 10^{\circ} \mathrm{S}$ to the equator, there is a zonally elongated area of moderate variance. Thus, the two bands of large variance are remarkable in exhibiting a line-symmetric shape with respect to $\sim 5^{\circ} \mathrm{N}$. As shown later, the two bands correspond to the pathways of the westward propagating twin vortices. As in the tropics, large variance is also observed in the subtropics and the mid-latitudes, surrounding the TP except in the eastern/southeastern area. At $500 \mathrm{hPa}$, the two zonal bands of high variance also appear in the tropics (Fig. 9b). A large variance maximum appears centered on the western TP. The $200 \mathrm{hPa} \psi$ variance shows local maxima at $50^{\circ} \mathrm{E}, 80^{\circ} \mathrm{E}$ and $110^{\circ} \mathrm{E}$ along $\sim 40^{\circ} \mathrm{N}$ along the Asian subtropical jet (Fig. 9a). A local center of large variance is also found over the head of Bay of Bengal, extending northwestward and connecting the large-variance area 


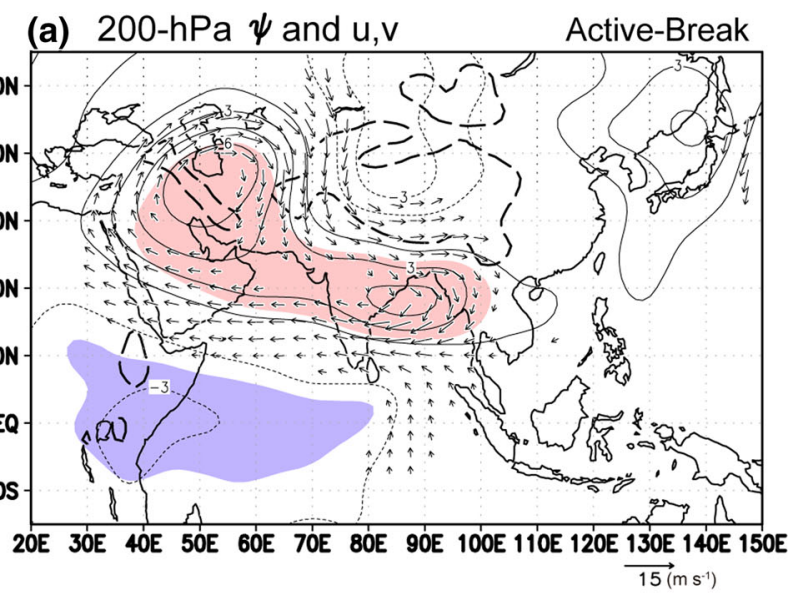

(b) 500-hPa $\psi$ and u,v
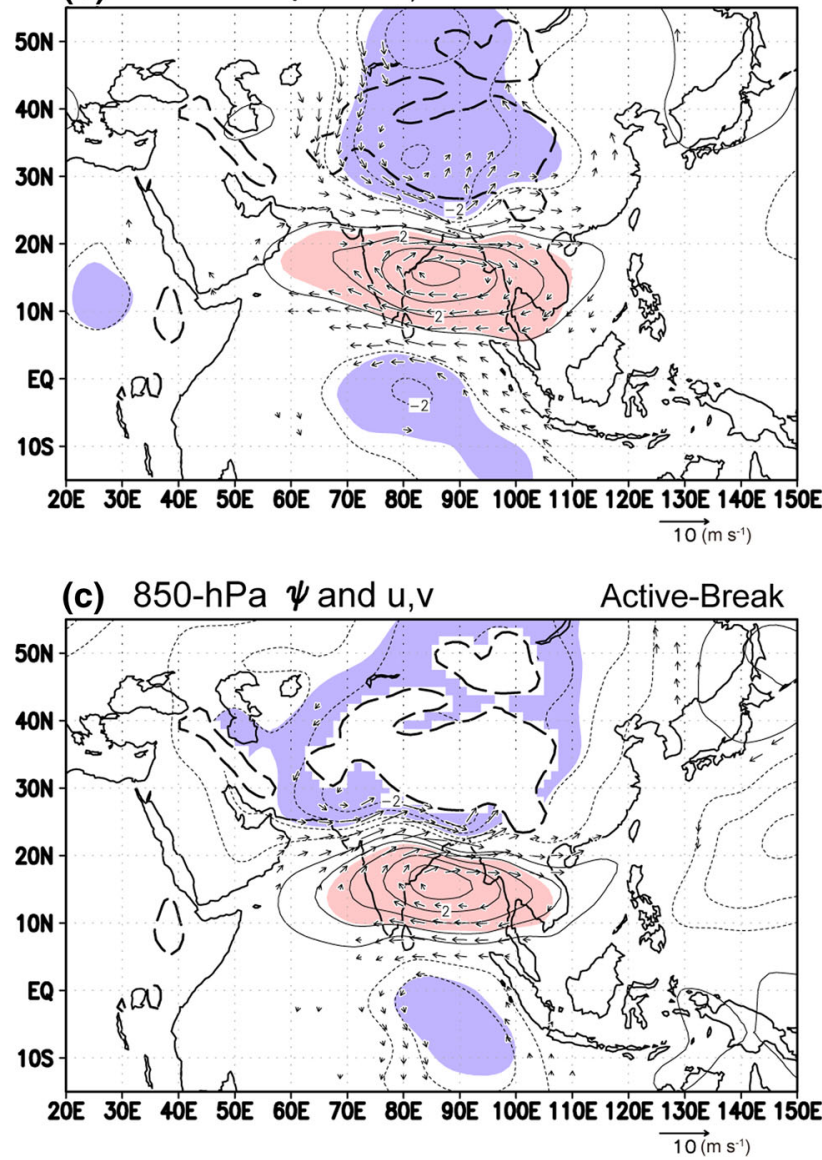

Fig. 8 Composite difference of a 200-hPa streamfunction $(\psi)$ and wind vectors between peak active and peak break days. Shading denotes statistically significant areas at the $99 \%$ level in the $\psi$ difference. The topographic contour for $3,000 \mathrm{~m}$ is shown as a thick dashed line. The contour interval for $\psi$ is $1.5 \times 10^{6} \mathrm{~m}^{2} \mathrm{~s}^{-1}$. b As in a but for $500 \mathrm{hPa}$. The contour interval for $\psi$ is $1.0 \times 10^{6} \mathrm{~m}^{2} \mathrm{~s}^{-1}$. c As in a but for $850 \mathrm{hPa}$. The contour interval for $\psi$ is $0.5 \times 10^{6} \mathrm{~m}^{2} \mathrm{~s}^{-1}$

around the Asian jet. No robust signals appeared in the mid-latitudes of the Southern Hemisphere (figure not shown). (a) Variance (200-hPa streamfunction)

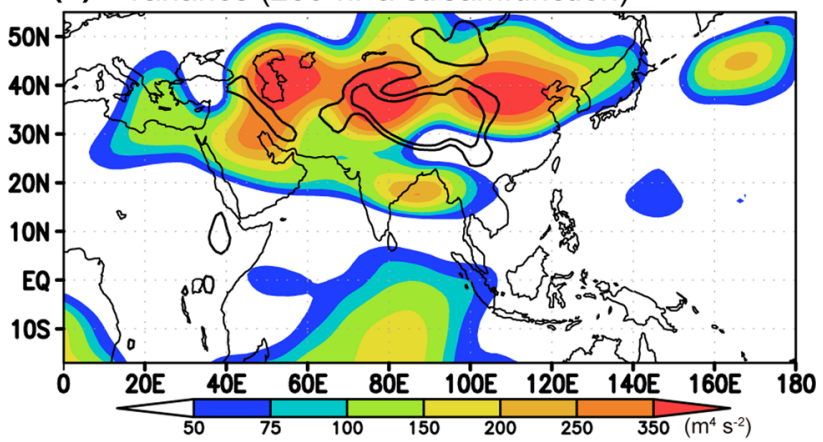

(b) Variance (500-hPa streamfunction)

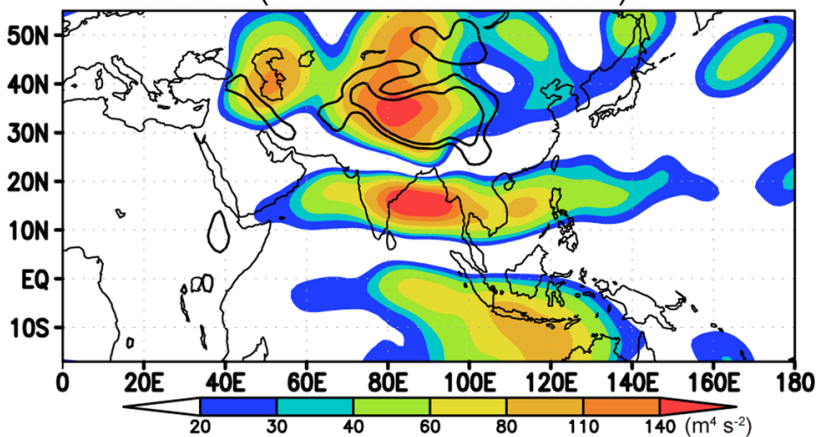

(c) Variance (850-hPa streamfunction)

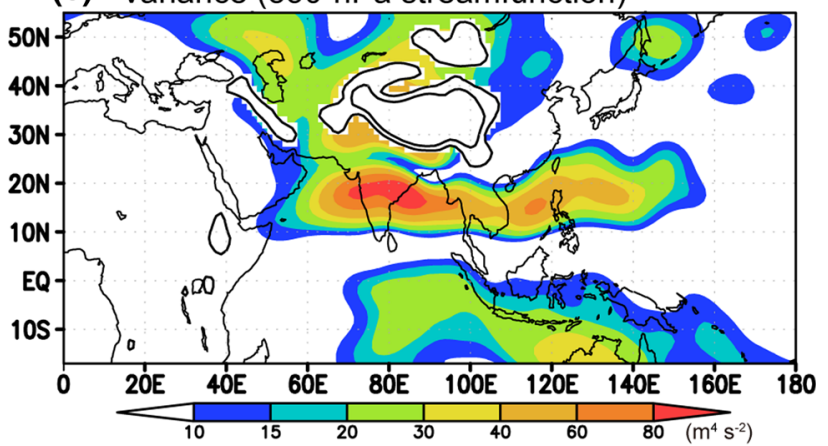

(d) Variance (OLR)

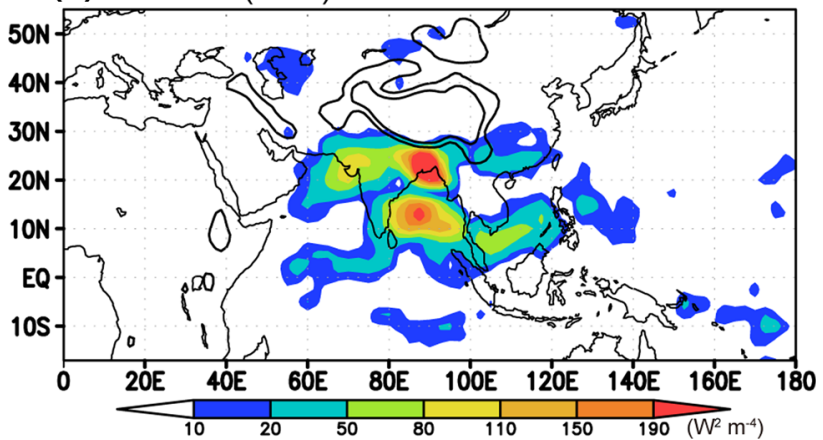

Fig. 9 a Variance in the 200-hPa streamfunction (shaded) in the composite life cycle (from day -5 to day +5 ). Topographic contours for 1,500 and 3,000 $\mathrm{m}$ are shown as a thick solid line. $\mathbf{b}$ As in a but for $500 \mathrm{hPa}$. c As in a but for $850 \mathrm{hPa}$. d As in a but for OLR

Figure 10 demonstrates the temporal sequence of the composites for the $850 \mathrm{hPa}$ streamfunction $\left(\psi_{850}\right)$, wind vectors, and OLR fields, based on the submonthly-scale 
Fig. 10 a-f Composites of the 850 -hPa streamfunction $\left(\psi_{850}\right.$; contours), wind vectors, and OLR (shaded) anomalies from day -5 to day 0 with reference to the 7-25-day rainfall anomalies over the MBWM. OLR anomalies less (greater) than -5 (5) $\mathrm{Wm}^{-2}$ are shaded; Shaded areas of OLR nearly correspond to areas of $99 \%$ confidence. Only wind vectors statistically significant at the $99 \%$ level are plotted. The contours of topographic contours for 1,500 and $3,000 \mathrm{~m}$ are shown as dashed lines. The contour interval for $\psi_{850}$ is $3.0 \times 10^{5} \mathrm{~m}^{2} \mathrm{~s}^{-1}$. Zero contours in $\psi_{850}$ are omitted

850-hPa $\psi$, wind vector and OLR anomalies

(a) Day -5

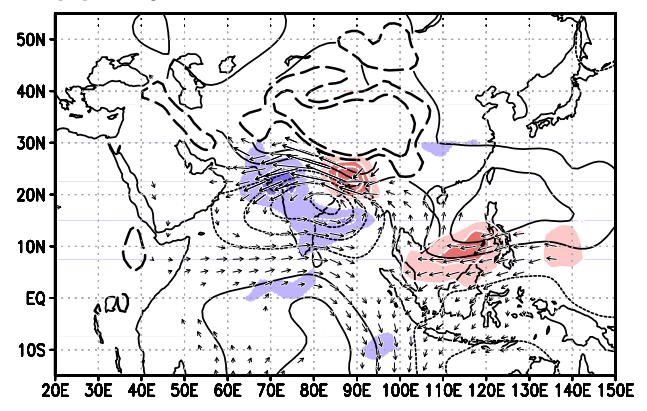

(b) Day -4

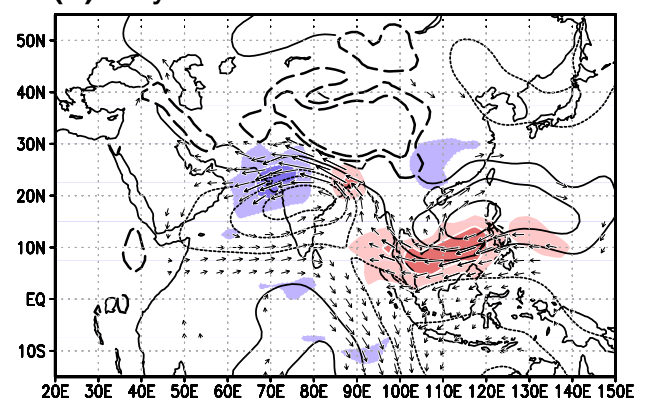

(c) Day -3

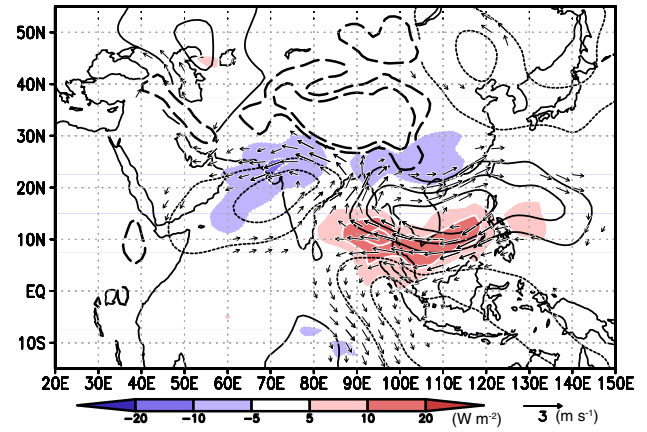

(d) Day -2

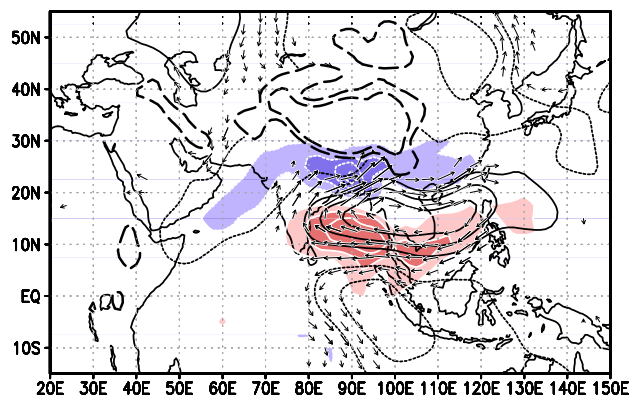

(e) Day -1

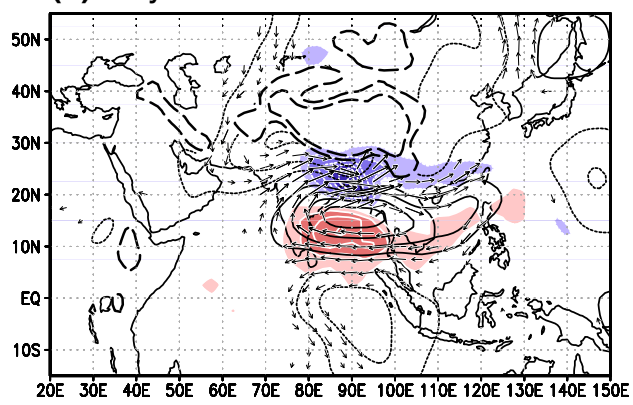

(f) Day 0 (peak active phase)

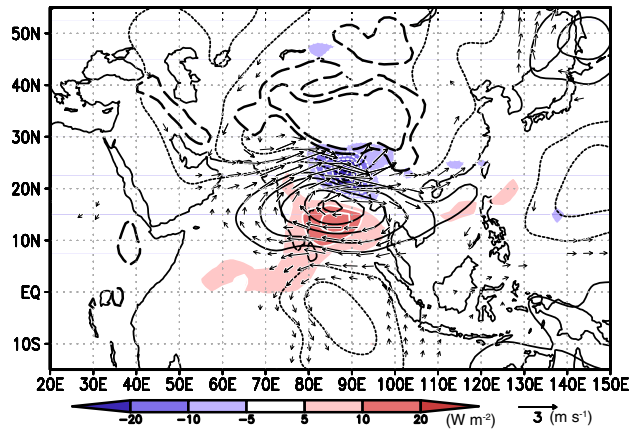

rainfall ISO over the MBWM. A striking feature of the $850 \mathrm{hPa}$ atmospheric circulation is the westward propagating twin vortices (i.e., twin lows or highs) with centers around $\sim 15^{\circ} \mathrm{N}$ and $\sim 5^{\circ} \mathrm{S}$ (Fig. 10). In day -5 , suppressed convection appears over the MBWM where the easterly/ southeasterly anomaly dominates in the northern periphery of a cyclonic anomaly over the east coast of central India. Another cyclonic circulation is observed with a center around $5^{\circ} \mathrm{S}, 80^{\circ} \mathrm{E}$. Thus, the anomaly distribution exhibits a twin-low structure. At day -4 , the next twin-vortex structure emerges from the South China Sea to the area around the maritime continent. The easterly anomaly is accelerated over the South China Sea along $5^{\circ}-7^{\circ} \mathrm{N}$ between the two anti-cyclonic vortices, and in turn convection is suppressed there. From day -4 to day -2 , the northern vortex moves westward from the South China Sea to the Bay of Bengal. On day -2 , a strong low-level southwesterly flows into the MBWM and convection becomes enhanced there. Note that a northerly intrudes from the mid-latitudes through a lowland area around $30^{\circ} \mathrm{N}, 60^{\circ} \mathrm{E}$ between the western TP and the Zagros Mountains (thick dashed line from $40^{\circ} \mathrm{N}, 40^{\circ} \mathrm{E}$ to $30^{\circ} \mathrm{N}$, $55^{\circ} \mathrm{E}$ ) from day -1 to day 0 . The enhanced northerly flows into the northernmost part of the Arabian Sea. Then the northerly changes direction into a westerly, merging with the southwesterly along the northwestern periphery of the anticyclone over the Bay of Bengal. On day 0, when convection/precipitation reaches a maximum, the anticyclonic anomaly is centered on the Bay of Bengal. A narrow cyclonic circulation deepens just south of the TP (Fig. 10f). The anomaly structure forms a strong westerly/southwesterly anomaly around the MBWM.

The half zonal wavelength of these vortices is $\sim 3,000-3,500 \mathrm{~km} \quad$ (Figs. 8c, 10f), approximately 
equivalent to zonal wavenumber 6 around the equator. The wave has westward phase speed of about $6.5 \mathrm{~m} \mathrm{~s}^{-1}$ around the equator from the time sequence. The horizontal structure and propagation characteristics are consistent with those found by Chen and Chen (1993), Yokoi and Satomura (2005), and Chatterjee and Goswami (2004) of $n=1$ equatorial Rossby waves with submonthly period. The two vortices are not symmetric about the equator, but appear to be shifted northward by $\sim 5-7^{\circ} \mathrm{N}$, consistent with the results of Chatterjee and Goswami (2004). Figure 11 shows time-longitude sections of the OLR anomaly (with only the seasonal cycle of OLR removed) and Rossbywave filtered OLR anomaly averaged from $10-20^{\circ} \mathrm{N}$ during June to August 1988. The Rossby-wave filter is a bandpass filter in the frequency-wavenumber domain to detect $n=1$ equatorial Rossby (ER) waves (e.g., Masunaga 2007; Kiladis et al. 2009). Here, we adopted the ER wave filter used by Masunaga (2007). The filter is defined for $-10 \leq \mathrm{k}<0$ ( $\mathrm{k}$ is the horizontal zonal wavenumber) and two dispersion relations with an equivalent depth of 5 and $100 \mathrm{~m}$. Note that remarkable westward OLR anomalies were observed in the summer of 1988 and these anomalies correspond well with the ER-wave-filtered anomalies. When largeamplitude ER waves with a positive (negative) OLR anomaly pass over the area around $90^{\circ} \mathrm{E}$ from June to midJuly, rainfall increases (decreases) remarkably over the MBWM (Fig. 11b), consistent with the composites shown in Fig. 10. Eastward shifts of large amplitude ER wave filtered anomalies can also be observed during the same period, which may be an eastward energy dispersion of the ER wave (i.e., group velocity) (e.g., Kiladis and Wheeler 1995). After mid-July, the ER wave signals passing over $\sim 90^{\circ} \mathrm{E}$ weaken and the amplitude of the ISO in rainfall over MBWM becomes small but the same tendency can be found even after mid-July.

The sequence of 500-hPa circulation anomalies shows that the spatial structure and its evolution are quite similar to that at $850 \mathrm{hPa}$ in the tropics, and $\psi$ anomalies become prominent in the mid-latitudes (Fig. 12). On day -4 , an anomalous low emerges centered on $40^{\circ} \mathrm{N}, 120^{\circ} \mathrm{E}$. Simultaneously, the north-south twin-high structure becomes obvious along approximately $115^{\circ} \mathrm{E}$. From days -4 to -2 , although the twin-high anomalies in the tropics move westward, the cyclonic anomaly to the east of the TP remains almost stationary and contributes to form a westerly anomaly over southern China. On day -1 , the cyclonic circulation appears to move into the TP rapidly and then induces a strong westerly anomaly over the MBWM to the south of the TP, in conjunction with the anti-cyclonic anomaly over the Bay of Bengal. On day 0 , the cyclonic circulation becomes further strengthened over the TP.

In the upper troposphere, a notable feature of the $\psi_{200}$ anomaly is a wavetrain structure along $40^{\circ} \mathrm{N}$ where the axis

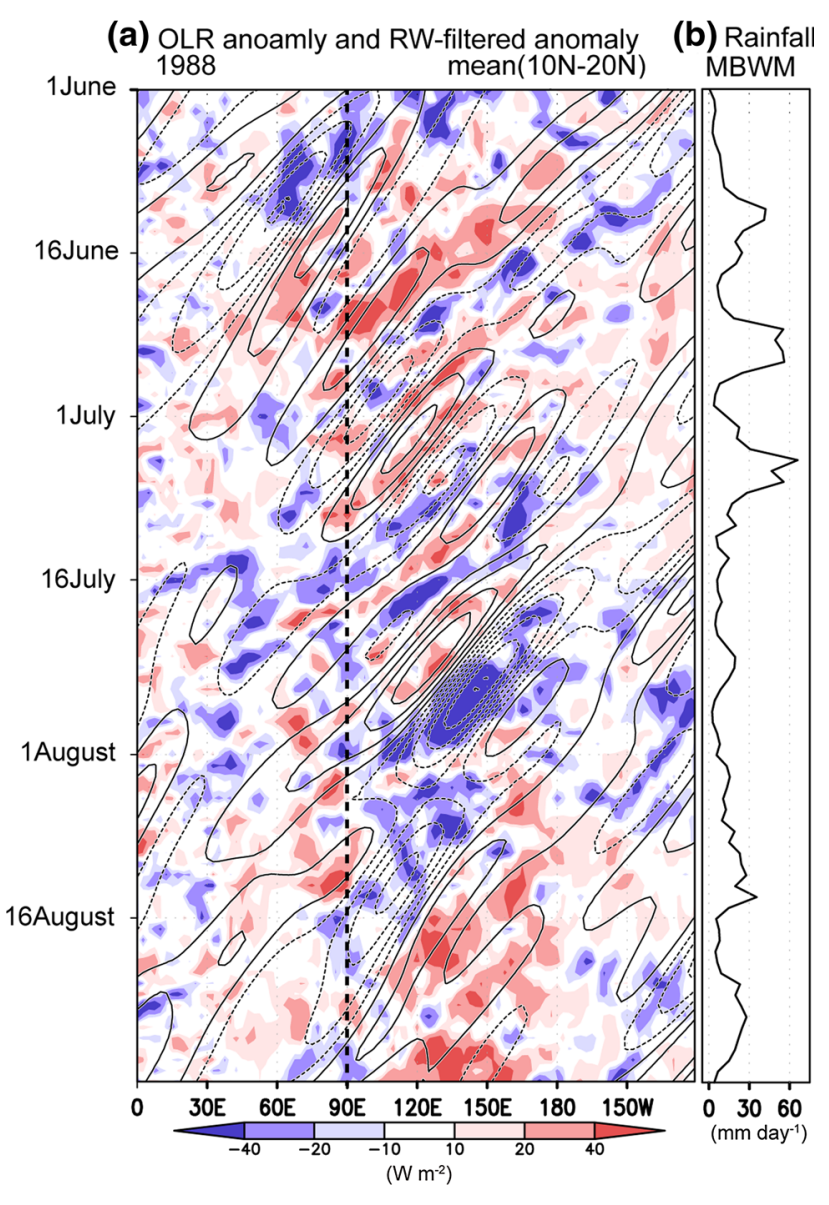

Fig. 11 a Time-longitude section of the OLR anomaly (shaded) and Rossby-wave-filtered OLR anomaly (contours) averaged between $10^{\circ}$ and $20^{\circ} \mathrm{N}$ in 1988 . b Time series of summer rainfall in 1988 in the MBWM region. OLR anomaly is calculated by subtracting the seasonal cycle from the raw time series. Contours of the filtered OLR anomaly are shown from -3 and $3 \mathrm{Wm}^{-2}$ at $6 \mathrm{Wm}^{-2}$ intervals. Zero contours are omitted. See the text for details of the Rossby wave filter

of the Asian jet is located (Fig. 13). From days -5 to -3 , the $\psi_{200}$ anomalies along the Asian jet move slowly westward. An eastward development of the anomalies is also observed (Fig. 13a-c). By day -2 , the anticyclonic $\psi_{200}$ anomaly over the TP seen on day -5 moves to $40^{\circ} \mathrm{N}, 55^{\circ} \mathrm{E}$ and develops in almost same position by day 0 . From day -3 to day 0 , the cyclonic circulation to the east of the TP moves westward slowly to the TP, accompanied with active convection signals to its south. The waves along the Asian jet $\left(\sim 40^{\circ} \mathrm{N}\right)$ have a wavenumber of $\sim 4.5$, with a phase speed of $\sim-$ $2.7 \mathrm{~m} \mathrm{~s}^{-1}$, as estimated from the composite sequence. The zonal phase speed of the mid-latitude barotropic Rossby wave relative to the background flow is given as

$c-\bar{u}=-\frac{\beta}{k^{2}+l^{2}}$,

where $c$ is the zonal phase speed, $\bar{u}$ is the background zonal wind speed, $k$ and $l$ are the zonal and meridional wave 


\section{0-hPa $\psi$, wind vector and OLR anomalies}

(a) Day -5

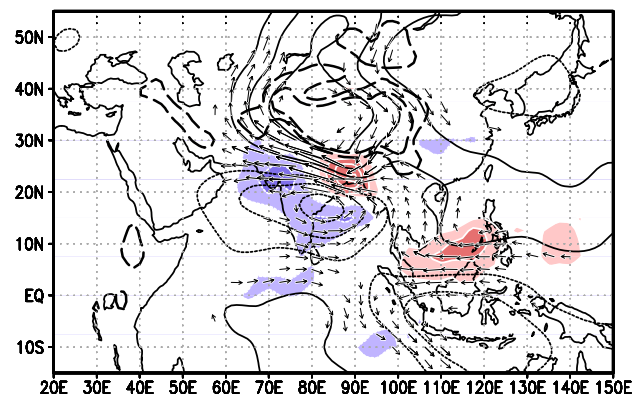

(b) Day -4

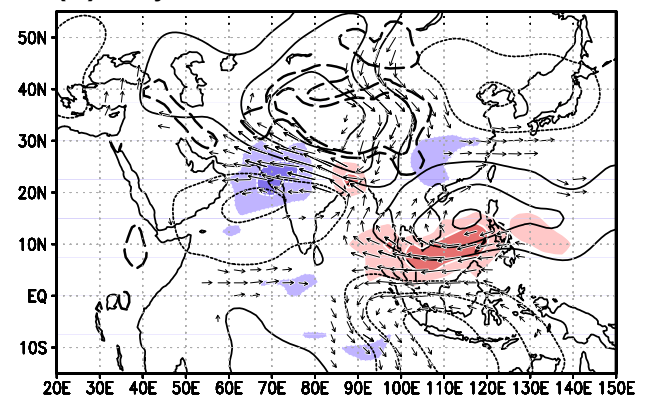

(c) Day -3

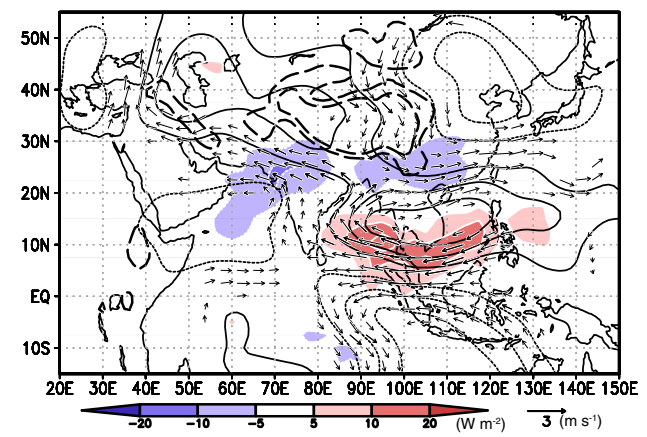

(d) Day -2

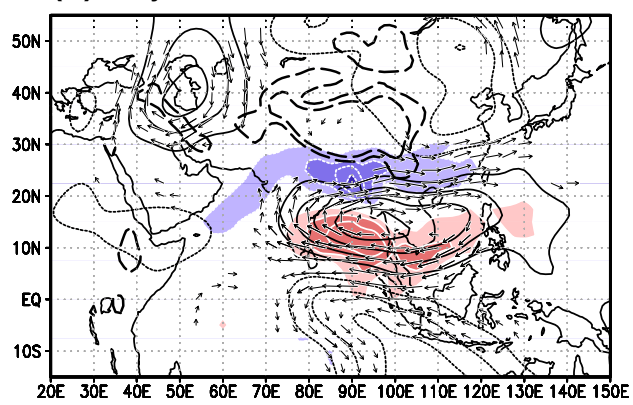

(e) Day -1

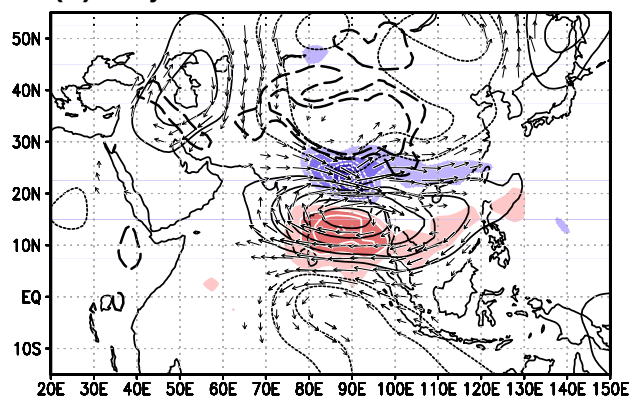

(f) Day 0 (peak active phase)

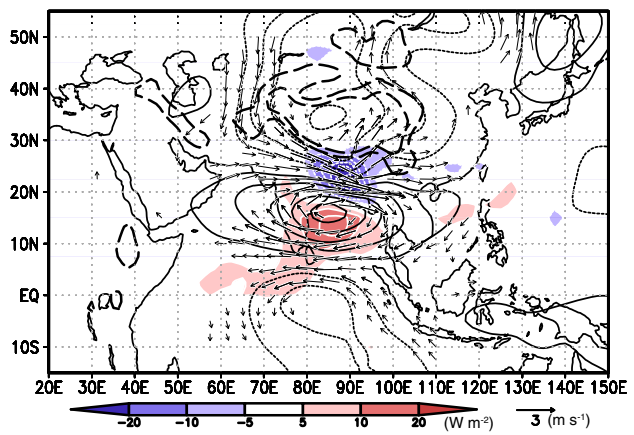

Fig. 12 As in Fig. 10 but for $500 \mathrm{hPa}$. The contour interval for $\psi_{500}$ is $4.0 \times 10^{5} \mathrm{~m}^{2} \mathrm{~s}^{-1}$

numbers, respectively, and $\beta$ is the meridional gradient of the Coriolis parameter. We can assume that the zonal and meridional wavenumbers are of similar scale $(k \approx l)$ (Holton 1992). The value of $\beta$ is $1.75 \times 10^{-11} \mathrm{~m}^{-1} \mathrm{~s}^{-1}$ at $40^{\circ} \mathrm{N}$. The zonal wavenumber is $\sim 4.5$. Hence, the Rossby wave speed relative to the background flow calculated from Eq. (2) is $10.6 \mathrm{~m} \mathrm{~s}^{-1}$. Here, the background zonal wind for the barotropic Rossby waves is defined as the vertical mean zonal flow in summer and is $\sim 8.0 \mathrm{~m} \mathrm{~s}^{-1}$ (Fujinami and Yasunari 2009). Hence, the phase speed of the waves relative to the ground is $\sim-2.6 \mathrm{~m} \mathrm{~s}^{-1}$, consistent with the observed phase speed of the waves along the Asian jet. To the south of the TP, a weak anticyclonic circulation covers the active convection area over the MBWM. The anti-cyclonic circulation is strengthened as the convection becomes stronger in the MBWM. The upper-level convergence to the south of the anti-cyclone covers the area of suppressed convection over the Bay of Bengal. After day 0, an anticyclonic anomaly develops rapidly to the east of the TP, indicative of downstream development of the anomaly, and then wholly moves westward (not shown).

The $\psi$ anomaly over the Bay of Bengal at the peak phase has a nearly barotropic vertical structure throughout the troposphere, while the large $\psi$ anomaly at $5^{\circ} \mathrm{S}$ is confined to below $500 \mathrm{hPa}$ (Figs. 10f, 12f, 13f). This feature is similar to those reported by Chen and Chen (1993) and Chatterjee and Goswami (2004). The vertical structure of the $\psi$ anomaly around the TP also displays a near barotropic nature. Note that the vertical baroclinic structure is evident in the $\psi$ anomaly just over the MBWM, probably associated with diabatic heating due to the high rainfall there. However, the zonal wind anomaly shows vertical 
Fig. 13 As in Fig. 10 but for $200 \mathrm{hPa}$. The contour interval for $\psi_{200}$ is $6.0 \times 10^{5} \mathrm{~m}^{2} \mathrm{~s}^{-1}$

\section{0-hPa $\psi$, wind vector and OLR anomalies}

(a) Day -5

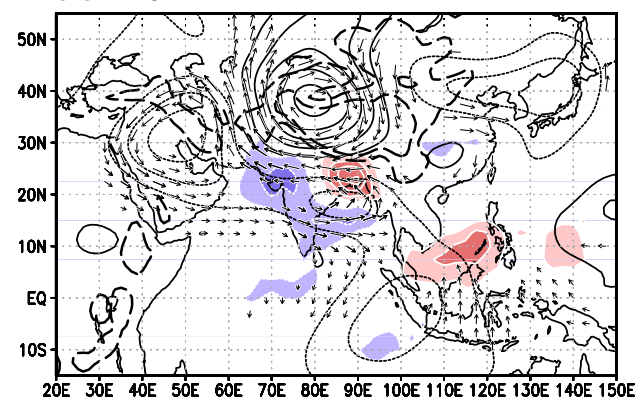

(d) Day -2

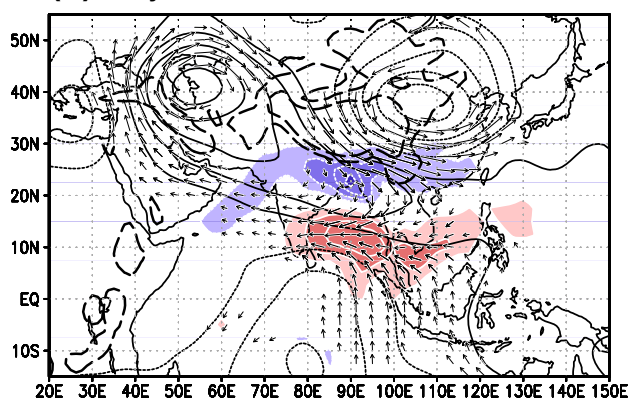

(b) Day -4

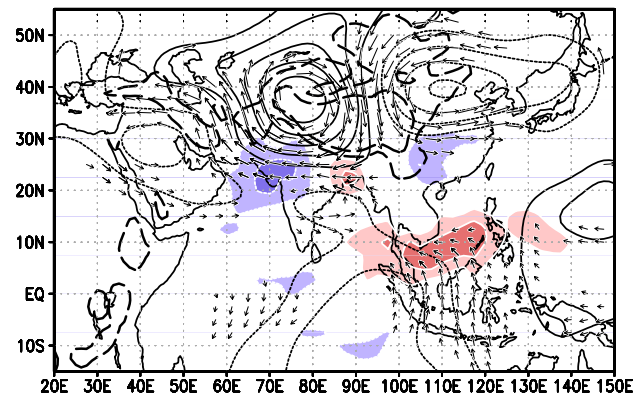

(e) Day -1

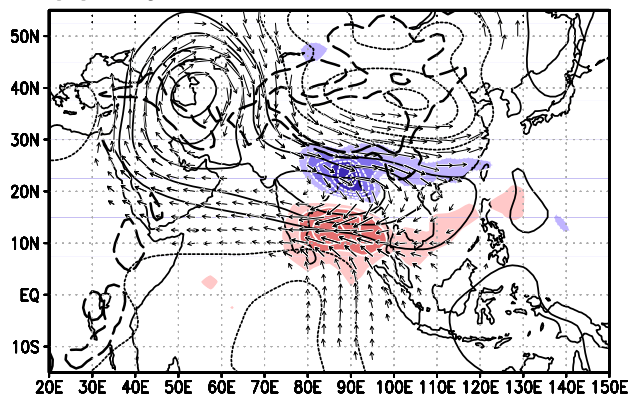

(c) Day -3

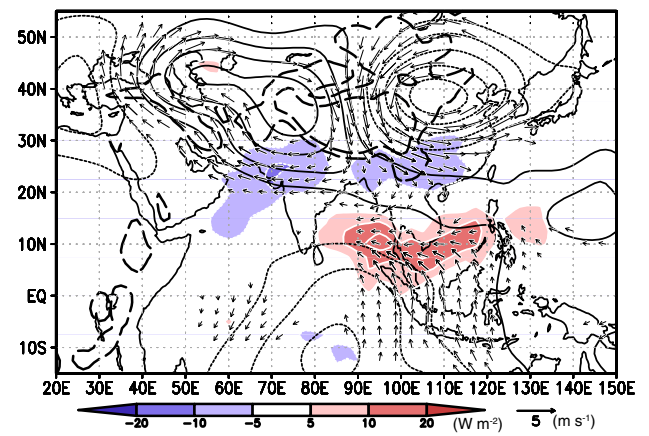

(f) Day 0 (peak active phase)

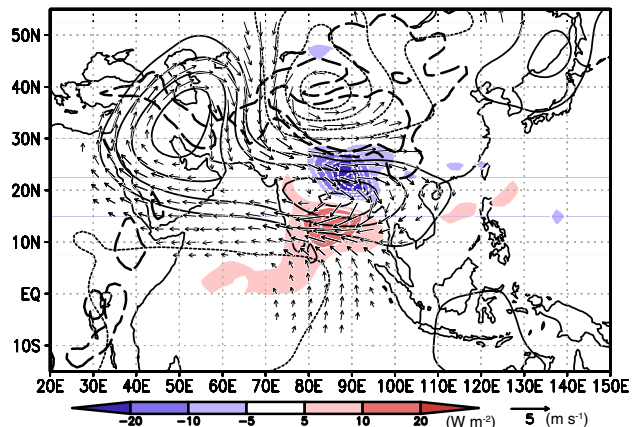

in-phase structure over the MBWM throughout the troposphere (not shown).

\section{Discussion}

5.1 The dynamics of distinct submonthly-scale ISO over the MBWM

The rainfall distribution and rainfall amount, related to the ISO, are highly controlled by regional-scale topography around the MBWM such as the Meghalaya Plateau and the coastline from southeastern Bangladesh to western Myanmar, just to the west of the Chittagong Hill Tracts and Arakan Mountains (Figs. 4, 5). These essential terrain features lie on the easternmost part of the Gangetic Plain, which is an east-west flat lowland area extending to the south of the Himalayas/TP. The plain is also surrounded by the mountainous regions of India (e.g., Chota Nagpur Plateau) to its south (Fig. 1). Thus, the plain and the surrounding topography likely help to enhance low-level zonal wind fluctuations along the plain, behaving like a duct for the low-level atmospheric circulation (Fig. 3d). Strong westerly/southwesterly flow enhances the orographic lifting of low-level moisture in the windward area of the mountains, which results in a large increase in precipitation in the area. A region away from mountainous area of the MBWM also gets high rainfall probably due to the low-level convergence, associated with the large cyclonic vorticity over Bangladesh. A recent study revealed that a closed low pressure system of the horizontal scale of $\sim 600 \mathrm{~km}$ often appears centered on Bangladesh in the active ISO phase over the MBWM and produces large amounts of rainfall in both the plain and mountainous areas 
(Hatsuzuka et al. 2013, submitted). The center of cyclonic vorticity over Bangladesh seen in Fig. 4a reflects the effects of the lows. The narrow cyclonic circulation reaching a height of up to $\sim 7,000 \mathrm{~m}$ just over the Gangetic Plain in the active phase, along with the shape of the surrounding regional mountains, likely provide favorable environmental conditions for the genesis of such a mesoscale vortex or low around the MBWM (Figs. 4a, 7b, c). Thus, the MBWM region has environmental conditions that concentrate a low-level moisture flux convergence there in the active phase.

The $n=1$ equatorial Rossby (ER) wave is a key agent that regulates the low-level zonal wind on submonthly timescales around the Gangetic Plain to the south of the TP and controls the periodicity of the ISO around the MBWM. Note that the rainfall over the MBWM is not directly induced by the convection coupled with the ER wave, but the westerly/southwesterly flow in the northern periphery of the anticyclonic vortex over the Bay of Bengal provides a suitable condition for enhancing precipitation around the MBWM. In contrast, over the Bay of Bengal and central India, the westward moving convection of the ER wave brings rain. The twin-vortex structure of the ER waves shifts northward by $\sim 5^{\circ} \mathrm{N}$ relative to the equator. This northward shift probably allows the northern part of the northern vortex to interact with the regional-scale topography around the MBWM efficiently. Chatterjee and Goswami (2004) explained the reason for the northward shift of the ER waves in the Indian Ocean in the Northern Hemisphere summer using the 'dynamic equator' concept. The mean flow over the Indian Ocean at low levels shows that the 'dynamic equator,' where ambient absolute vorticity is zero, shifts to around $5^{\circ} \mathrm{N}$ during summer and results in a shift of the ER waves towards the north by about $5^{\circ}$. The ambient absolute vorticity fields are controlled by the large-scale mean Asian summer monsoon flow, which is induced by the north-south heat contrast between the Eurasian continent and the Indian Ocean (Fig. 7c, f). Thus, the strong Asian summer monsoon circulation itself could help to displace the ER waves northward. The shifted ER waves can effectively induce strong horizontal fluctuations on submonthly timescales to the south of the TP, and in turn rainfall increases distinctly on the same timescales over the MBWM. Additionally, large diabatic heating due to the high precipitation around the MBWM contributes to maintain strong Asian monsoon circulation.

Meanwhile, the mid-latitude atmospheric circulation also seems to play an active role in enhancing the zonal wind fluctuation to the south of the TP. The $\psi_{200}$ anomaly along the Asian jet $\left(\sim 40^{\circ} \mathrm{N}\right)$ has almost vertically barotropic structure around the TP (Figs. 10, 12, 13). The negative $\psi_{200}$ anomaly to the east of the TP moves westward to the TP from days -2 to -1 (Fig. 13d, e). Concurrently, a negative $\psi_{500}$ anomaly appears over the TP (Fig. 12e). The $\psi_{500}$ anomaly increases an east-west pressure gradient along the western periphery of the TP and a north-south pressure gradient along the southern periphery. A similar time sequence is also observed at $850 \mathrm{hPa}$; cyclonic circulation is strengthened from the western through to the southern periphery of the TP (Fig. 10e). This means that the monsoon trough just to the south of the TP deepens. Thus, the westward moving vertically barotropic cyclonic circulation enhances the low and mid-level northerly to the west of the TP and the westerly to the south of the TP (Figs. 10e, 12e).

In short, the equatorial wave and the mid-latitude wave probably enhance the submonthly-scale low-level zonal wind fluctuation to the south of the TP synchronously, and the interaction between the zonal wind fluctuation and the regional-scale topography causes a distinct rainfall ISO on the same timescale over the MBWM.

\subsection{Covariability of atmospheric circulation between the tropics and mid-latitudes}

The results demonstrate a robust connection between the tropics and the mid-latitudes, associated with the distinct rainfall ISO over the MBWM region. However, the mechanism of this linkage remains unclear. A possible interpretation is that diabatic heating related to the submonthly-scale ISO may induce a Rossby-wave response along the Asian jet in the mid-latitudes. Note that the convection and low-level circulation anomalies over the MBWM remain in almost the same location from the initiation to termination of the active ISO phase (Figs. 6, $10)$, whereas convection and circulation anomalies over the Bay of Bengal and central India clearly move westward from the South China Sea to northwestern India (Fig. 10). The anomalous active convection/rainfall over central-northwestern India could excite or reinforce the upper-level high to its north over the Asian jet through Rossby response from days -5 to -3 (Figs. 6a-c, 13a-c) (e.g., Ambrizzi and Hoskins 1997; Krishnan and Sugi 2001; Ding and Wang 2007). The enhanced anticyclone induces the downstream development of a wave train due to eastward Rossby wave dispersion along the Asian jet (Enomoto et al. 2003; Fujinami and Yasunari 2004). Therefore, the cyclonic anomaly with barotropic structure likely forms downstream of the anticyclonic anomaly as a part of the wave train by day -4 . The anticyclonic anomaly over the western TP is elongated westward and enhances rapidly at around $40^{\circ} \mathrm{N}, 55^{\circ} \mathrm{E}$ from day -3 to day -2 . Then, the cyclonic anomaly to the east of the TP moves westward over the TP, accompanied by an active convection band to its south. Meanwhile, the existence of 
the Himalayas/TP massif may transform the Rossby response in the active phase of the MBWM because lowand mid-level flow is highly restricted by topography. The enhancement of the westerly in the low/middle troposphere to the south of the TP could be interpreted as a response to diabatic heating due to high rainfall under such restricted conditions. In the active ISO phase over the MBWM, a trough lies just to the south of the Himalayas/ TP from the low level to $400 \mathrm{hPa}$ (i.e., 7,500 m). From 700 to $400 \mathrm{hPa}$, the airflow from the mid-latitudes directly intrudes into the MBWM along the southwestern/southern periphery of the TP (Fig. 7b). In contrast, the air flow of mid-latitude origin in the break ISO cannot intrude into the MBWM, as it is inhibited by a strong easterly to the south of the TP (Fig. 7c). Thus, the mid-latitude circulation can interact physically with the tropical circulation to the south of the TP in the active phase of ISO in the MBWM. The circulation anomalies between the area around the TP and the Bay of Bengal are reflected by such interactions (Fig. 8b). In any case, the horizontal structure of the atmospheric circulation anomaly seems to be greatly affected by the TP topography. The existence of the TP may link submonthly-scale ISO between the tropics and the mid-latitudes through the enhancement in vertically barotropic circulation. Numerical modeling research is needed to investigate the cause of the linkage between the tropics and the mid-latitudes associated with distinct submonthly-scale ISO over MBWM and the effects of the Himalayas/TP on forming submonthly-scale circulation signals around the TP.

\section{Summary}

The present study investigated the detailed rainfall distribution related to the submonthly (7-25-day)-scale ISO around the MBWM region. The associated three-dimensional atmospheric circulation and time-evolution features were investigated for the whole Asian summer monsoon system from the tropics to the mid-latitudes using APHRODITE, TRMM-PR, and JRA25 reanalysis datasets.

The MBWM region, where a tremendous amount of rainfall is observed in summer, is the most dominant area of submonthly-scale ISO among the Asian summer monsoon regions. A distinct rainfall ISO is caused by the lowlevel zonal wind fluctuations and its interaction with the regional-scale topographical features around the MBWM, with a remarkable alternation between westerly and easterly flow. In the active phase of the ISO over the MBWM, a low-level westerly/southwesterly prevails over the MBWM and a center of cyclonic vorticity appears over Bangladesh. Therefore, the wind components normal to the windward slopes of the Meghalaya Plateau, the Chittagong
Hill Tracts, and the western coast of Myanmar are enhanced; high rainfall $\left(\geq 50 \mathrm{~mm} \mathrm{day}^{-1}\right)$ is then observed over these regions due to the orographic lifting of moist air. Relatively high rainfall $\left(\geq 20 \mathrm{~mm} \mathrm{day}^{-1}\right.$ ) in the lowland area of the MBWM away from the regional-scale mountains is due to frictional convergence in the boundary layer under strong low-level cyclonic circulation.

The distinct alternation of the low-level zonal wind around the MBWM is caused by the westward propagating vortex pair with zonal wavenumber $\sim 6$ and westward phase speed of $\sim 6.5 \mathrm{~m} \mathrm{~s}^{-1}$ in the tropics, which is consistent with the $\mathrm{n}=1 \mathrm{ER}$ wave. The centers of the vortices propagate westward along $\sim 15^{\circ} \mathrm{N}$ and $5^{\circ} \mathrm{S}$. Thus, the twinvortex structure of the ER wave shifts northward by $5^{\circ}$, likely due to the large north-south asymmetric nature of the ambient Asian summer monsoon circulation in the tropics. The northern vortex can affect the MBWM region. As the anticyclonic vortex moves into the Bay of Bengal, the westerly/southwesterly becomes strengthened around the MBWM, which is covered by the northern fringe of the anticyclonic vortex. Additionally, the MBWM region is located in the easternmost part of the Gangetic Plain, an east-west flat lowland that is surrounded to the north and south by high-elevation areas (i.e., the Himalayas/TP and the Chota Nagpur Plateau). The topographic features of the Gangetic Plain enhance the zonal wind fluctuation, and westerly/southwesterly flow brings high rainfall on submonthly timescales around the MBWM.

Additionally, robust circulation signals relevant to the ISO appear over the mid-latitudes over the MBWM. In the upper troposphere, a wavetrain structure is evident along the Asian subtropical jet. The waves have a Rossby wavelike structure with a zonal wavenumber of $\sim 4.5$ and a westward phase speed relative to the ground of $\sim 2.7 \mathrm{~m} \mathrm{~s}^{-1}$, consistent with the theory of mid-latitude barotropic Rossby waves in terms of the zonal phase speed relative to the mean background wind. In addition to the slow westward propagation, the eastward development of the new center of action is observed along the Asian jet, indicative of Rossby wave energy dispersion along the waveguide of the Asian jet. The waves have barotropic vertical structure around the TP. In the active phase of the ISO over the MBWM, the cyclonic anomaly dominates throughout the troposphere around the TP. This is associated with the deepening of the monsoon trough just to the south of the TP. Thus, the cyclonic anomaly to the south of the TP enhances the north-south pressure gradient and in turn enhances the westerly flow in conjunction with the anticyclonic anomaly over the Bay of Bengal.

The robust circulation and convection signals relevant to the ISO extend across the whole Asian summer monsoon system from the tropics to the mid-latitudes over the MBWM region. The submonthly-scale ISO in rainfall 
around the MBWM becomes obvious on the local scale $(\sim 500 \mathrm{~km})$, although the atmospheric circulation causing the ISO has a horizontal scale of $\sim 6,000 \mathrm{~km}$ or more extending across the whole Asian monsoon system.

Diurnal variation is also a dominant fluctuation in rainfall/convection around the MBWM (Ohsawa et al. 2001; Hirose et al. 2008; Takahashi et al. 2010; Biasutti et al. 2012). The relationship between the submonthlyscale ISO and diurnal variation has been presented in previous studies that analyzed a single year (e.g., Ohsawa et al. 2000; Terao et al. 2006; Sato 2013). Sato (2013) pointed out the importance of the nocturnal low-level jet (LLJ) appearing around $900 \mathrm{hPa}$ for enhancing orographic rainfall around the Meghalaya Plateau. The direction of the LLJ varies with the diurnal cycle, which accelerates the pre-existing southwesterly flow (e.g., Fig. 5 a) between 18 and 06 local time in the active ISO phase. Thus, the diurnal variation in the LLJ causes the evening to early morning maximum of precipitation. The change in atmospheric circulation related to submonthly-scale ISO around the MBWM provides different atmospheric environments for the diurnal variation and meso-scale disturbances. Further statistical analysis is needed to clarify the multi-timescale interaction with the submonthly-scale ISO. Establishing why the 30-60-day ISO is so weak around the MBWM is also an important area for future research.

Acknowledgments We thank the anonymous reviewers for their constructive comments. We also thank Drs. T. Hayashi, R. Kawamura, M. Satoh, H. Masunaga, T. Sato, S. Yokoi, Y. Fukutomi, and H. Kanamori for their helpful discussions. This study was conducted with support from a Grant-in-Aid for Scientific Research (B22340137) and a Grant-in-Aid for Scientific Research for Young Scientists (B-24740320) from the Japan Society for the Promotion of Sciences (JSPS). Portions of this study were conducted as part of a collaborative research program of the Hydrospheric Atmospheric Research Center, Nagoya University. The APHRODITE dataset was obtained from the project web site (http://www.chikyu.ac.jp/precip/).

Open Access This article is distributed under the terms of the Creative Commons Attribution License which permits any use, distribution, and reproduction in any medium, provided the original author(s) and the source are credited.

\section{References}

Ambrizzi T, Hoskins BJ (1997) Stationary Rossby-wave propagation in a baroclinic atmosphere. Q J R Meteorol Soc 123:919-928

Annamalai H, Slingo JM (2001) Active/break cycles: diagnosis of the intraseasonal variability of the Asian summer monsoon. Clim Dyn 18:85-102

Biasutti M, Yuter SE, Burleyson CD, Sobel AH (2012) Very high resolution rainfall patterns measured by TRMM precipitation radar: seasonal and diurnal cycles. Clim Dyn 39:239-258. doi:10.1007/s00382-011-1146-6
Chatterjee P, Goswami BN (2004) Structure, genesis and scale selection of the tropical quasi-biweekly mode. Q J R Meteorol Soc 130:1171-1194. doi:10.1256/Qj.03.133

Chen TC, Chen JM (1993) The 10-20-day mode of the 1979 Indian monsoon: its relation with the time-variation of monsoon rainfall. Mon Weather Rev 121:2465-2482

Ding Q, Wang B (2007) Intraseasonal teleconnection between the summer Eurasian wave train and the Indian monsoon. J Clim 20:3751-3767

Duchon CE (1979) Lanczos filtering in one and two dimensions. J Appl Meteorol 18:1016-1022

Enomoto T, Hoskins BJ, Matsuda Y (2003) The formation mechanism of the Bonin high in August. Q J R Meteorol Soc 129:157-178

Fujinami H, Yasunari T (2001) The seasonal and intraseasonal variability of diurnal cloud activity over the Tibetan Plateau. J Meteor Soc Jpn 79:1207-1227

Fujinami H, Yasunari T (2004) Submonthly variability of convection and circulation over and around the Tibetan Plateau during the boreal summer. J Meteor Soc Jpn 82:1545-1564

Fujinami H, Yasunari T (2009) The effects of midlatitude waves over and around the Tibetan Plateau on submonthly variability of the East Asian summer monsoon. Mon Weather Rev 137:2286-2304. doi:10.1175/2009mwr2826.1

Fujinami H, Hatsuzuka D, Yasunari T, Hayashi T, Terao T, Murata F, Kiguchi M, Yamane Y, Matsumoto J, Islam MN, Habib A (2011) Characteristic intraseasonal oscillation of rainfall and its effect on interannual variability over Bangladesh during boreal summer. Int J Climatol 31:1192-1204. doi:10.1002/joc. 2146

Hirose M, Oki R, Shimizu S, Kachi M, Higashiuwatoko T (2008) Finescale diurnal rainfall statistics refined from eight years of TRMM PR data. J Appl Meteorol Climatol 47:544-561. doi:10. 1175/2007jamc1559.1

Holton JR (ed) (1992) Atmospheric oscillations: linear perturbation theory. An introduction to dynamic meteorology, 3rd edn, Chap 7. Academic Press, London, pp 183-227

Hoskins BJ, Rodwell MJ (1995) A model of the Asian summer monsoon: 1. The Global-Scale. J Atmos Sci 52:1329-1340

Hoyos CD, Webster PJ (2007) The role of intraseasonal variability in the nature of Asian monsoon precipitation. J Clim 20:4402-4424. doi:10.1175/Jcli4252.1

Iguchi T, Kozu T, Meneghini R, Awaka J, Okamoto K (2000) Rainprofiling algorithm for the TRMM precipitation radar. J Appl Meteorol 39:2038-2052

Kikuchi K, Wang B (2009) Global perspective of the quasi-biweekly oscillation. J Clim 22:1340-1359. doi:10.1175/2008jcli2368.1

Kiladis GN, Wheeler M (1995) Horizontal and vertical structure of observed tropospheric equatorial Rossby waves. J Geophys Res Atmos 100:22981-22997

Kiladis GN, Wheeler MC, Haertel PT, Straub KH, Roundy PE (2009) Convectively coupled equatorial waves. Rev Geophys 47:Rg2003. doi: $10.1029 / 2008$ rg000266

Krishnamurti TN, Ardanuy P (1980) 10 to 20-day westward propagating mode and breaks in the monsoons. Tellus 32(1):15-26

Krishnamurti TN, Bhalme HN (1976) Oscillations of a monsoon system. Part I. Observational aspects. J Atmos Sci 33:1937-1954

Krishnan R, Sugi M (2001) Baiu rainfall variability and associated monsoon teleconnections. J Meteor Soc Jpn 79:851-860

Liebmann B, Smith CA (1996) Description of a complete (interpolated) outgoing longwave radiation dataset. Bull Am Meteorol Soc 77:1275-1277

Madden RA, Julian PR (1994) Observations of the 40-50-day tropical oscillation: a review. Mon Weather Rev 122:814-837 
Masunaga H (2007) Seasonality and regionality of the Madden-Julian oscillation, Kelvin wave, and equatorial Rossby wave. J Atmos Sci 64:4400-4416. doi:10.1175/2007jas2179.1

Matthews AJ, Kiladis GN (1999) The tropical-extratropical interaction between high-frequency transients and the Madden-Julian oscillation. Mon Weather Rev 127:661-677

Moon J-Y, Wang B, Ha K-J, Lee J-Y (2013) Teleconnections associated with Northern Hemisphere summer monsoon intraseasonal oscillation. Clim Dyn 40:2761-2774. doi:10.1007/ s00382-012-1394-0

Murakami M (1976) Analysis of summer monsoon fluctuations over India. J Meteor Soc Jpn 54:15-31

Murata F, Terao T, Hayashi T, Asada H, Matsumoto J (2008) Relationship between atmospheric conditions at Dhaka, Bangladesh, and rainfall at Cherrapunjee, India. Nat Hazards 44:399-410. doi:10.1007/s11069-007-9125-2

Nesbitt SW, Anders AM (2009) Very high resolution precipitation climatologies from the Tropical Rainfall Measuring Mission precipitation radar. Geophys Res Lett 36:L15815. doi:10.1029/ $2009 \mathrm{~g} 1038026$

Ohsawa T, Hayashi T, Mitsuta Y, Matsumoto J (2000) Intraseasonal variation of monsoon activities associated with the rainfall over Bangladesh during the 1995 summer monsoon season. J Geophys Res Atmos 105:29445-29459

Ohsawa T, Ueda H, Hayashi T, Watanabe A, Matsumoto J (2001) Diurnal variations of connective activity and rainfall in tropical Asia. J Meteor Soc Jpn 79:333-352

Onogi K, Tsutsui J, Koide H, Sakamoto M, Kobayashi S, Hatsushika H, Matsumoto T, Yamazaki N, Kamahori H, Takahashi K, Kadokura S, Wada K, Kato K, Oyama R, Ose T, Mannoji N, Taira R (2007) The JRA-25 reanalysis. J Meteor Soc Jpn 85:369-432

Ose T (1998) Seasonal change of Asian summer monsoon circulation and its heat source. J Meteor Soc Jpn 76:1045-1063

Romatschke U, Houze RA (2011) Characteristics of precipitating convective systems in the South Asian monsoon. J Hydrometeorol 12:3-26. doi:10.1175/2010jhm1289.1

Sato T (2013) Mechanism of orographic precipitation around the Meghalaya Plateau associated with intraseasonal oscillation and the diurnal cycle. Mon Weather Rev 141:2451-2466. doi:10. 1175/MWR-D-12-00321.1

Shrestha D, Singh P, Nakamura K (2012) Spatiotemporal variation of rainfall over the central Himalayan region revealed by TRMM
Precipitation Radar. J Geophys Res Atmos 117:D22106. doi:10. 1029/2012JD018140

Singh P, Nakamura K (2010) Diurnal variation in summer monsoon precipitation during active and break periods over central India and southern Himalayan foothills. J Geophys Res Atmos 115:D12122. doi:10.1029/2009jd012794

Takahashi HG, Fujinami H, Yasunari T, Matsumoto J (2010) Diurnal rainfall pattern observed by Tropical Rainfall Measuring Mission Precipitation Radar (TRMM-PR) around the Indochina peninsula. J Geophys Res 115:D07109. doi:10.1029/2009jd012155

Terao T, Islam MN, Hayashi T, Oka T (2006) Nocturnal jet and its effects on early morning rainfall peak over northeastern Bangladesh during the summer monsoon season. Geophys Res Lett 33:L18806. doi:10.1029/2006g1026156

Wang B, Webster P, Kikuchi K, Yasunari T, Qi YJ (2006) Boreal summer quasi-monthly oscillation in the global tropics. Clim Dyn 27:661-675. doi:10.1007/s00382-006-0163-3

Xie SP, Xu HM, Saji NH, Wang YQ, Liu WT (2006) Role of narrow mountains in large-scale organization of Asian monsoon convection. J Clim 19:3420-3429

Yang J, Wang B, Bao Q (2010) Biweekly and 21-30-Day variations of the subtropical summer monsoon rainfall over the lower reach of the Yangtze River Basin. J Clim 23:1146-1159. doi:10.1175/ 2009jcli3005.1

Yasunari T (1979) Cloudiness fluctuations associated with the northern hemisphere summer monsoon. J Meteor Soc Jpn $57: 227-242$

Yatagai A, Arakawa O, Kamiguchi K, Kawamoto H, Nodzu MI, Hamada A (2009) A 44-year daily gridded precipitation dataset for Asia based on a dense network of rain gauges. SOLA 5:137-140. doi:10.2151/sola.2009-035

Yatagai A, Kamiguchi K, Arakawa O, Hamada A, Yasutomi N, Kitoh A (2012) APHRODITE: constructing a long-term daily gridded precipitation dataset for Asia based on a dense network of rain gauges. Bull Am Meteorol Soc 93:1401-1415

Yokoi S, Satomura T (2005) An observational study of intraseasonal variations over southeast Asia during the 1998 rainy season. Mon Weather Rev 133:2091-2104

Yokoi S, Satomura T, Matsumoto J (2007) Climatological characteristics of the intraseasonal variation of precipitation over the Indochina Peninsula. J Clim 20:5301-5315. doi:10.1175/ 2007jcli1357.1 